Supporting Information for

\title{
Electro-reductive Fragmentation of Oxidized Lignin Models
}

Cheng Yang, ${ }^{\dagger}$ Gabriel Magallanes, ${ }^{\dagger}$ Stephen Maldonado ${ }^{\dagger, \S}$ and Corey R. J. Stephenson $*, \uparrow$

$\dagger$ Willard Henry Dow Laboratory, Department of Chemistry, University of Michigan, 930 North University Avenue, Ann Arbor, Michigan 48109, United States.

$\S$ Program in Applied Physics, University of Michigan, Ann Arbor, Michigan 48109, United States.

* Email: crjsteph@umich.edu (C. R. J. S)

\section{Contents}

I. Reaction Progress for Electrochemical Reduction of 1a Monitored by GC-MS ---_---_-_-_

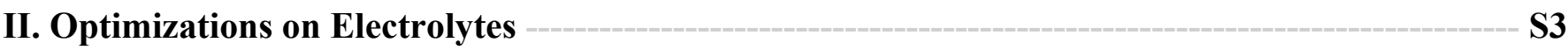

III. Cyclic Voltammograms for Reduction of 1a with Different Electrolytes --_-_-_-_S5

IV. Cyclic Voltammograms for Reduction of $1 \mathrm{a}-1 \mathrm{f}$ and $2 \mathrm{a}-2 \mathrm{f}$

V. Optimizations on Proton/hydrogen Source --_ S7

VI. Cyclic Voltammograms for Reduction of 1a and 1g: $\mathrm{MeCN}-\mathrm{H}_{3}$ vs. $\mathrm{MeCN}_{3} \mathrm{~d}_{3}-$

VII. Reaction Setup -- S9

VIII. ${ }^{1} \mathrm{H}$ NMR and ${ }^{13} \mathrm{C}$ NMR Spectra of Products $2 \mathrm{a}-2 \mathrm{~h}, 3 \mathrm{a}-3 \mathrm{~b}$ and $4 \mathrm{a}-4 \mathrm{f}$ 


\section{Reaction Progress for Electrochemical Reduction of 1a Monitored by GC-MS}

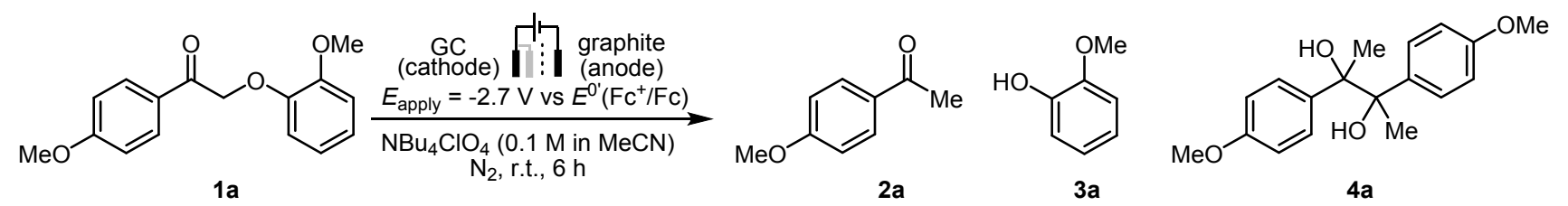

$1 a$

$2 a$

$3 a$

$4 a$

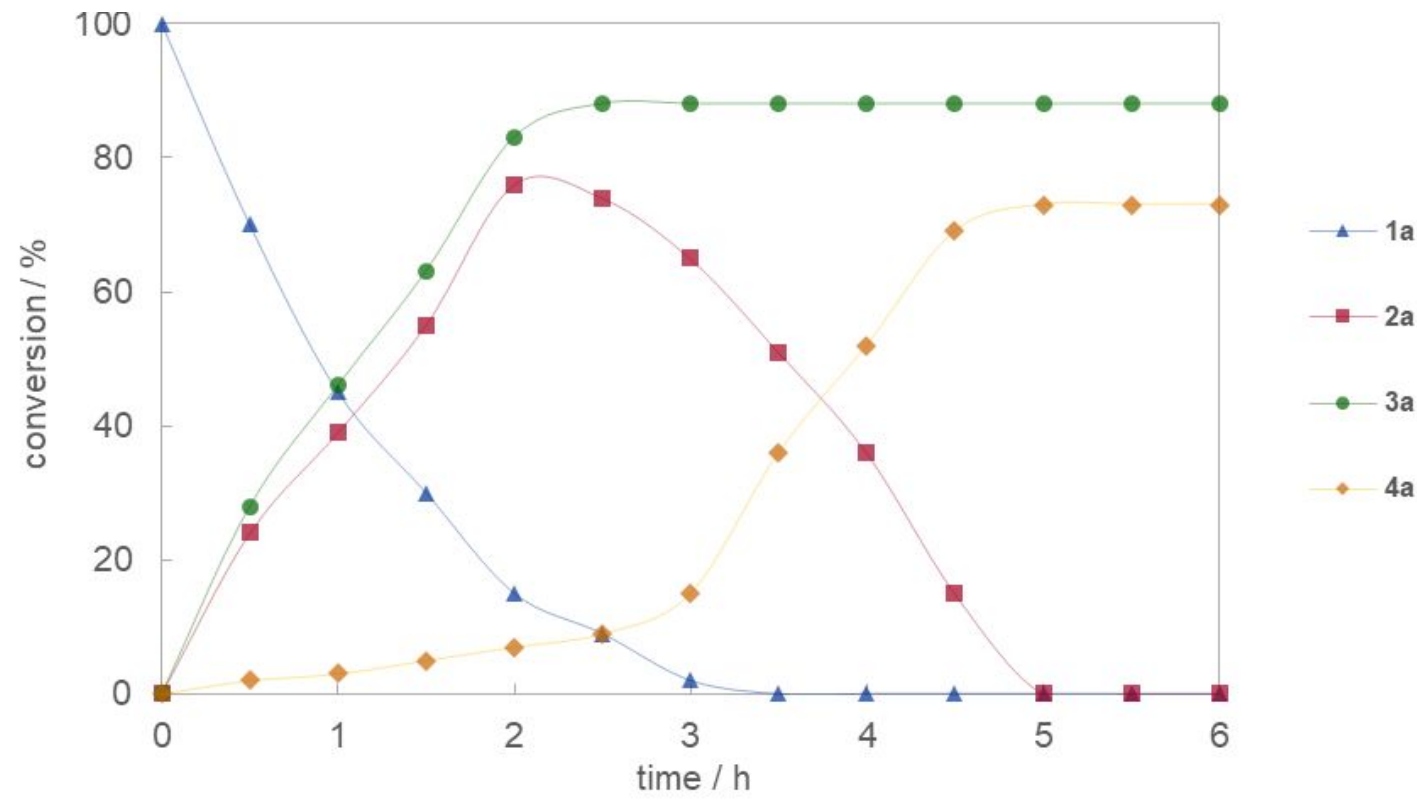

Figure S1. Reaction progress monitored by GC-MS.

Table S1. Raw data_Reaction progress monitored by GC-MS.

\begin{tabular}{|c|c|c|c|c|c|c|c|c|}
\hline time/h & \multicolumn{2}{|c|}{$\mathbf{1 a}$} & \multicolumn{2}{c|}{$\mathbf{2 a}$} & \multicolumn{2}{c|}{ 3a } & \multicolumn{2}{c|}{ 4a } \\
\hline & a.u. & conv/\% & a.u. & conv/\% & a.u. & conv/\% & a.u. & conv/\% \\
\hline 0 & 33309918 & 100 & 0 & 0 & 0 & 0 & 0 & 0 \\
\hline 0.5 & 23316943 & 70 & 4088181 & 24 & 34965299 & 28 & 327198 & 2 \\
\hline 1 & 14989463 & 45 & 6643295 & 39 & 57442991 & 46 & 490798 & 3 \\
\hline 1.5 & 9992975 & 30 & 9368749 & 55 & 78671923 & 63 & 817996 & 5 \\
\hline 2 & 4996488 & 15 & 12945908 & 76 & 103647136 & 83 & 1145194 & 7 \\
\hline 2.5 & 2997893 & 9 & 12605226 & 74 & 109890940 & 88 & 1472393 & 9 \\
\hline 3 & 666198 & 2 & 11072158 & 65 & 109890940 & 88 & 2453988 & 15 \\
\hline 3.5 & 0 & 0 & 8687385 & 51 & 109890940 & 88 & 5889572 & 36 \\
\hline 4 & 0 & 0 & 6132272 & 36 & 109890940 & 88 & 8507159 & 52 \\
\hline 4.5 & 0 & 0 & 2555113 & 15 & 109890940 & 88 & 11288345 & 69 \\
\hline 5 & 0 & 0 & 0 & 0 & 109890940 & 88 & 11942742 & 73 \\
\hline 5.5 & 0 & 0 & 0 & 0 & 109890940 & 88 & 11942742 & 73 \\
\hline 6 & 0 & 0 & 0 & 0 & 109890940 & 88 & 11942742 & 73 \\
\hline
\end{tabular}




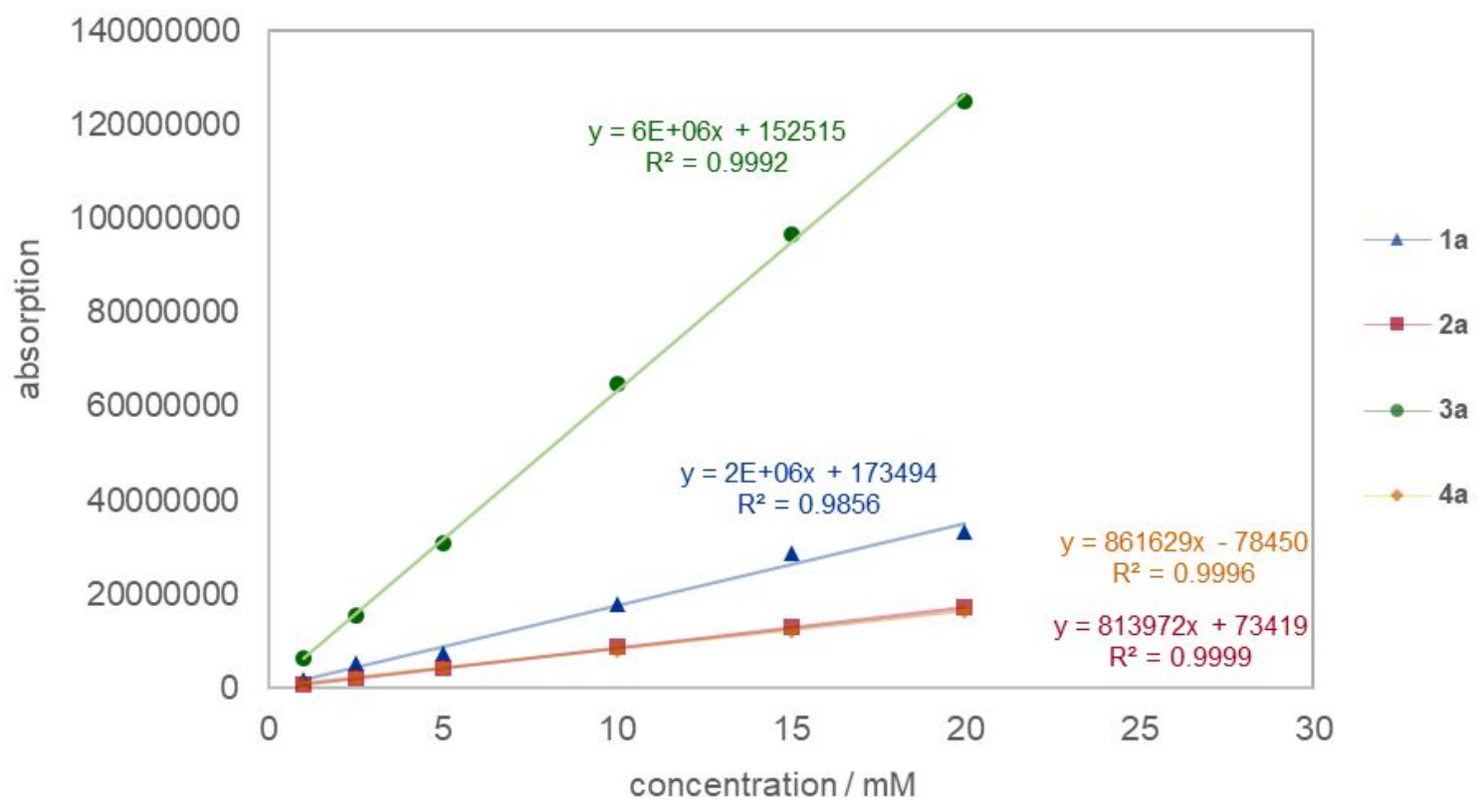

Figure S2. Calibration curves of 1a, 2a, 3a and 4a.

Table S2. Raw data_Calibration curves of 1a, 2a, 3a and 4a.

\begin{tabular}{|c|c|c|c|c|}
\hline c/mM & 1a/a.u. & 2a/a.u. & 3a/a.u. & 4a/a.u. \\
\hline 20 & 33309918 & 17034089 & 124876068 & 16359921 \\
\hline 15 & 28852939 & 12936917 & 96546301 & 12295641 \\
\hline 10 & 17752959 & 8717345 & 64837234 & 8179761 \\
\hline 5 & 7267180 & 4058372 & 30816767 & 4089380 \\
\hline 2.5 & 5139240 & 2127386 & 15578384 & 2244940 \\
\hline 1 & 1855696 & 752354 & 6343753 & 818376 \\
\hline
\end{tabular}




\section{Optimizations on Electrolytes}
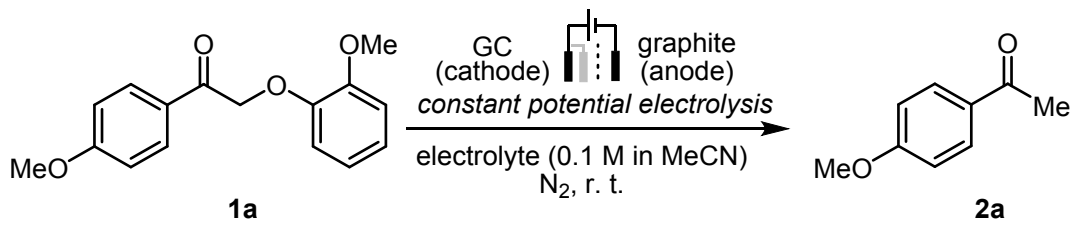

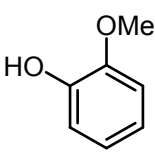

$3 a$<smiles>COc1ccc(C(C)(O)C(C)(O)c2ccc(OC)cc2)cc1</smiles>

$4 a$

Table S3. Optimizations on electrolyte.

\begin{tabular}{cccccccc} 
entry & electrolyte & $\begin{array}{c}\text { potential } \\
\text { vs Fc } \mathbf{F c}\end{array}$ & time & 2a yield & 3a yield & 4a yield & notes \\
\hline 1 & $\mathrm{NBu}_{4} \mathrm{ClO}_{4}$ & $-2.3 \mathrm{~V}$ & $4 \mathrm{~h}$ & $85 \%$ & $87 \%$ & - & difficult isolation \\
2 & $\mathrm{NBu}_{4} \mathrm{ClO}_{4}$ & $-2.7 \mathrm{~V}$ & $6 \mathrm{~h}$ & - & $85 \%$ & $72 \%$ & difficult isolation \\
3 & $\mathrm{NBu}_{4} \mathrm{PF}_{6}$ & $-2.3 \mathrm{~V}$ & $4 \mathrm{~h}$ & $<10 \%$ & - & - & difficult isolation \\
4 & $\mathrm{LiClO}_{4}$ & $-2.1 \mathrm{~V}$ & $4 \mathrm{~h}$ & $<10 \%$ & - & - & surface deactivation \\
5 & $\mathrm{NaClO}_{4}$ & $-2.1 \mathrm{~V}$ & $4 \mathrm{~h}$ & $<10 \%$ & - & - & surface deactivation \\
6 & $\mathrm{MgClO}_{4}$ & $-1.9 \mathrm{~V}$ & $4 \mathrm{~h}$ & $<10 \%$ & - & - & surface deactivation \\
7 & $\mathrm{KPF}_{6}$ & $-2.3 \mathrm{~V}$ & $4 \mathrm{~h}$ & $<10 \%$ & - & - & surface deactivation \\
8 & $\mathrm{NBu}_{4} \mathrm{Br}$ & $-2.3 \mathrm{~V}$ & $4 \mathrm{~h}$ & $86 \%$ & $92 \%$ & - & \\
9 & $\mathrm{NBu}_{4} \mathrm{Br}$ & $-2.7 \mathrm{~V}$ & $6 \mathrm{~h}$ & - & $86 \%$ & $75 \%$ & \\
10 & $\mathrm{NBu} 4 \mathrm{I}_{11}$ & $-2.3 \mathrm{~V}$ & $4 \mathrm{~h}$ & $82 \%$ & $88 \%$ & & \\
\hline
\end{tabular}


<smiles></smiles>

$3 a^{\prime}$

${ }^{1} \mathrm{H}$ NMR $\left(500 \mathrm{MHz}, \mathrm{D}_{2} \mathrm{O}\right)$
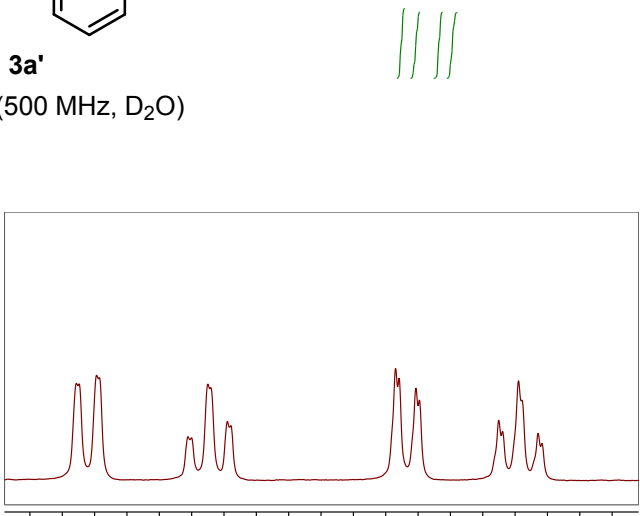

6.956 .906 .856 .806 .756 .706 .656 .606 .556 .50 f1 (ppm)

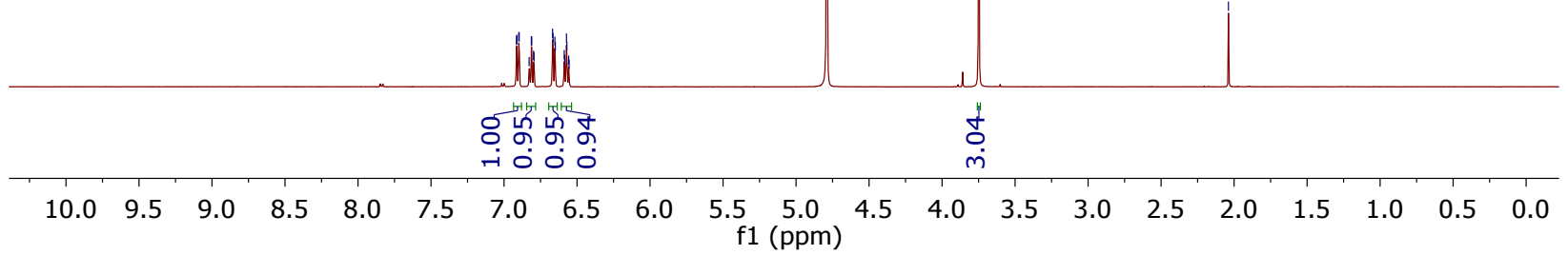

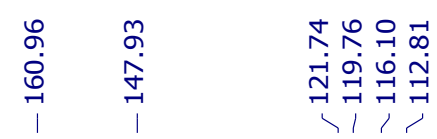

오ำ

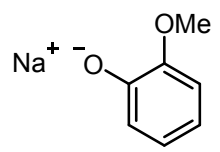

3a'

${ }^{1} \mathrm{H}$ NMR $\left(500 \mathrm{MHz}, \mathrm{D}_{2} \mathrm{O}\right)$

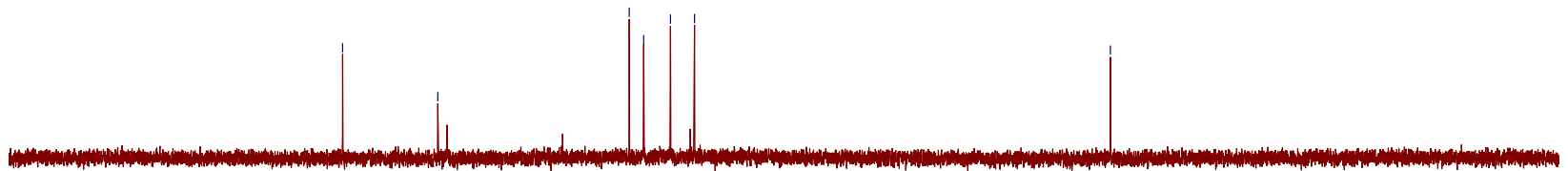




\section{Cyclic Voltammograms for Reduction of 1a with Different Electrolytes}
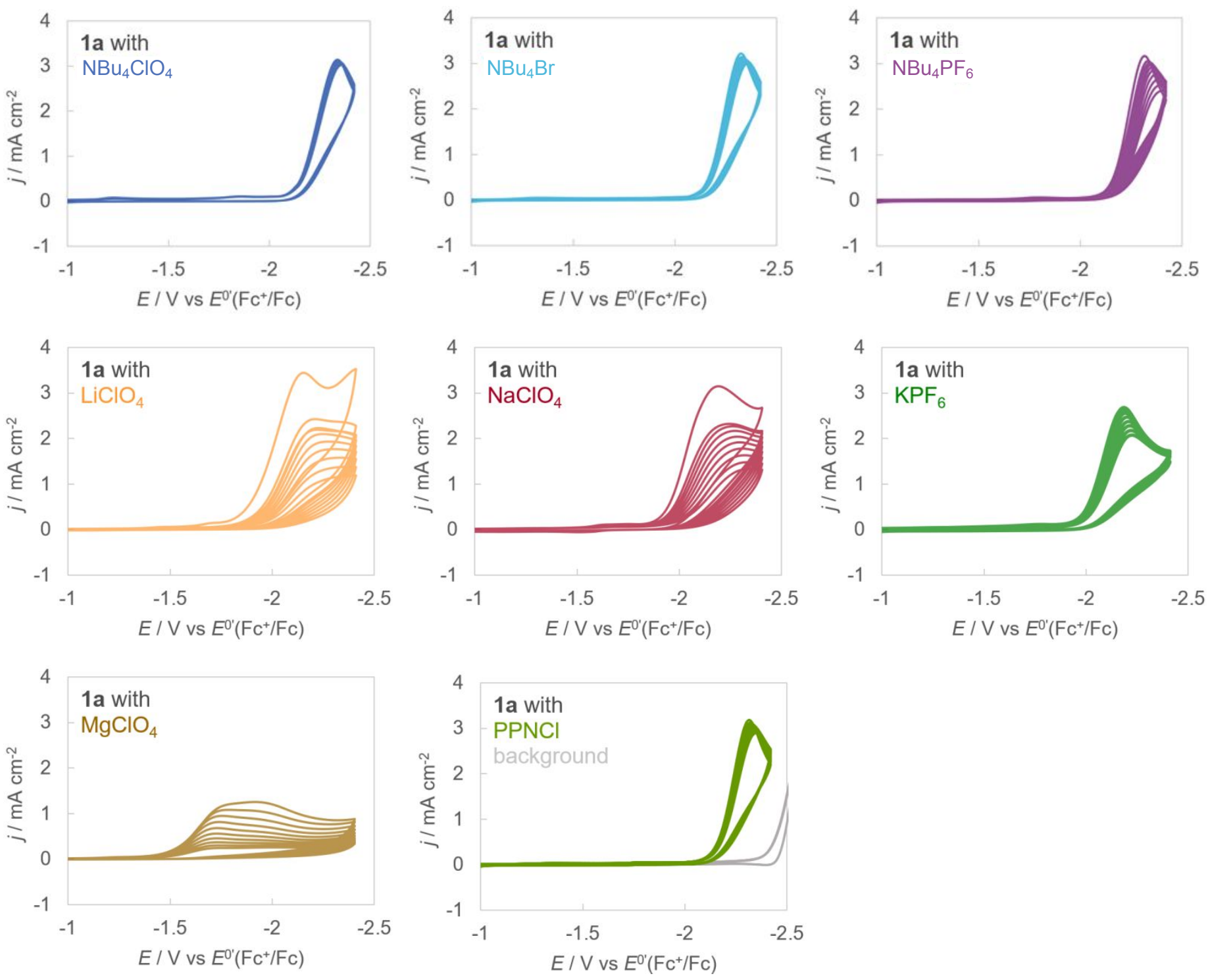

Figure S3. Cyclic voltammograms for reduction of $10 \mathrm{mM}$ 1a with $0.1 \mathrm{M}$ electrolyte in degassed $\mathrm{MeCN}$ at $0.1 \mathrm{Vs}^{-1}$ for 20 cycles. 
IV. Cyclic Voltammograms for Reduction of $1 \mathrm{a}-1 \mathrm{f}$ and $2 \mathrm{~b}-2 \mathrm{f}$
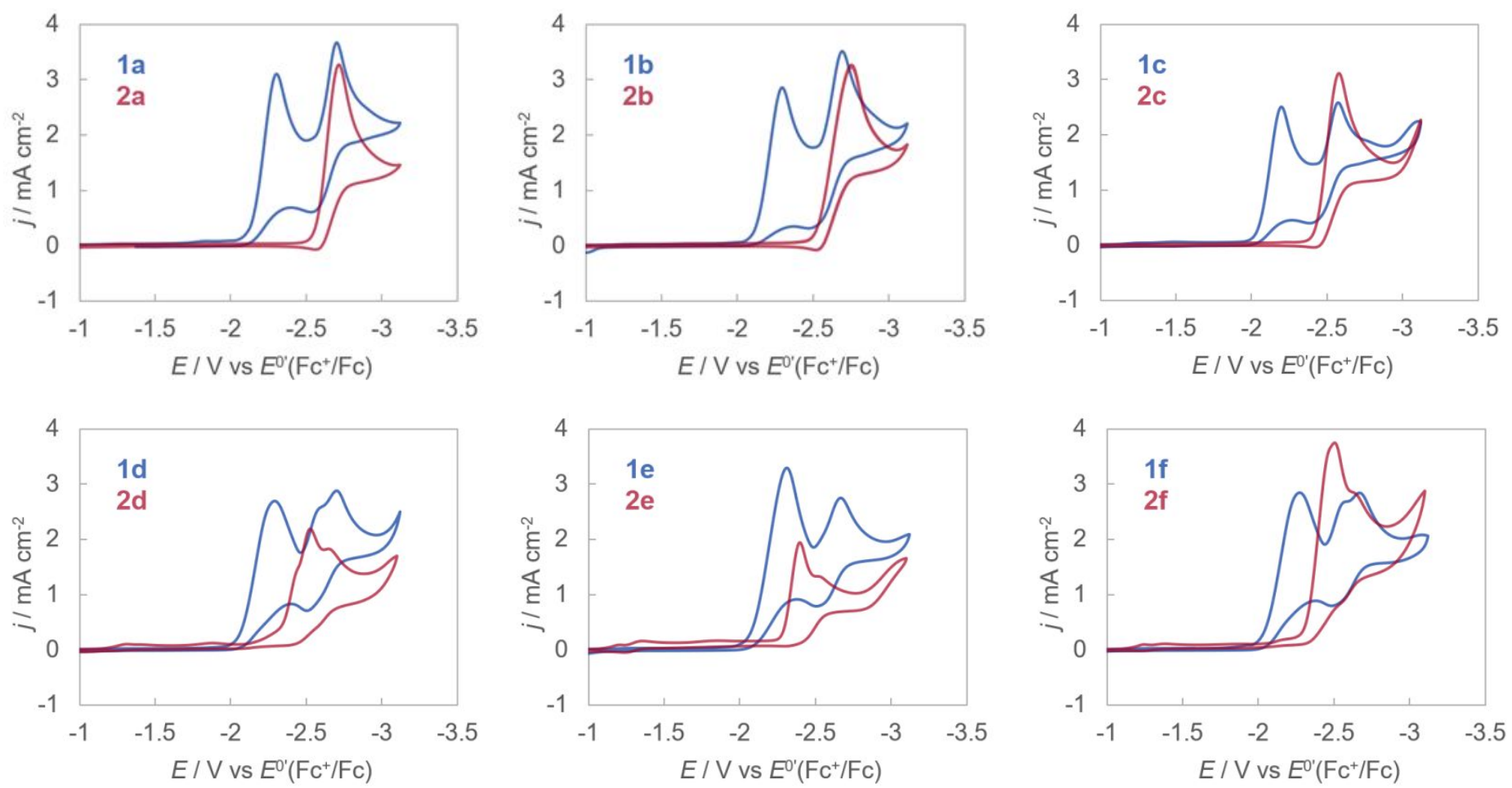

Figure S4. Cyclic voltammograms for reduction of $10 \mathrm{mM} 1$ and 2 with $0.1 \mathrm{M} \mathrm{NBu}_{4} \mathrm{Br}$ in degassed MeCN at $0.1 \mathrm{Vs}^{-1}$. 


\section{Optimizations on Proton/hydrogen Source}<smiles>COc1ccc(C(=O)C(CO)Oc2ccccc2OC)cc1</smiles>

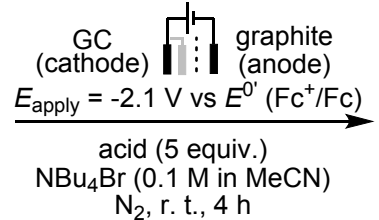

$\overbrace{2 d}^{11}$<smiles>COc1ccccc1O</smiles><smiles>COc1ccc(C(O)(CCO)C(O)(CCO)c2ccc(OC)cc2)cc1</smiles>

Table S4. Optimizations on proton/hydrogen source.

\begin{tabular}{cccccc} 
entry & acid (5 equiv.) & 2a yield & 3a yield & 4a yield & notes \\
\hline 1 & - & trace & $65 \%$ & trace & \\
2 & $\mathrm{HCO}_{2} \mathrm{H}$ & $50 \%$ & $40 \%$ & $15 \%$ & \\
3 & $\mathrm{AcOH}$ & $82 \%$ & $64 \%$ & $<5 \%$ & \\
4 & $p \mathrm{TsOH}$ & $10 \%$ & $10 \%$ & trace & $>85 \% \mathrm{RSM}$ \\
\hline
\end{tabular}

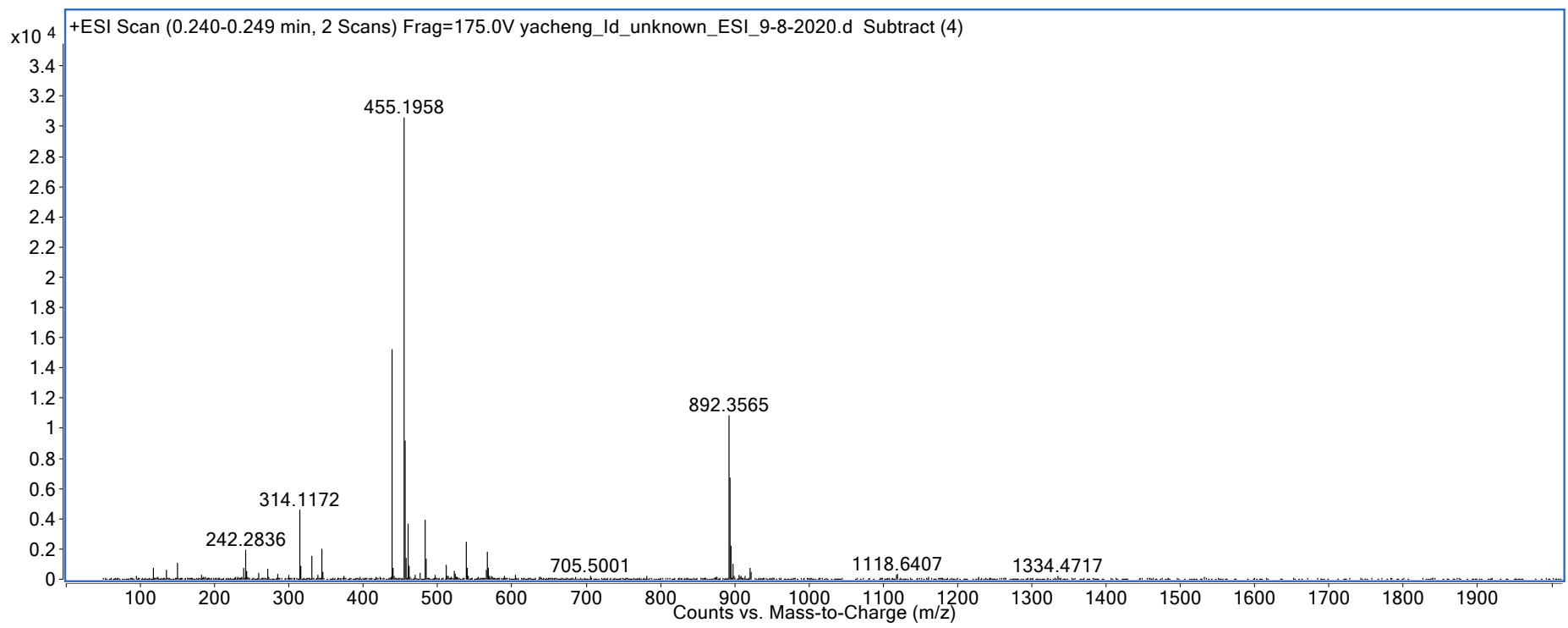

Figure S5. HRMS from entry 1.
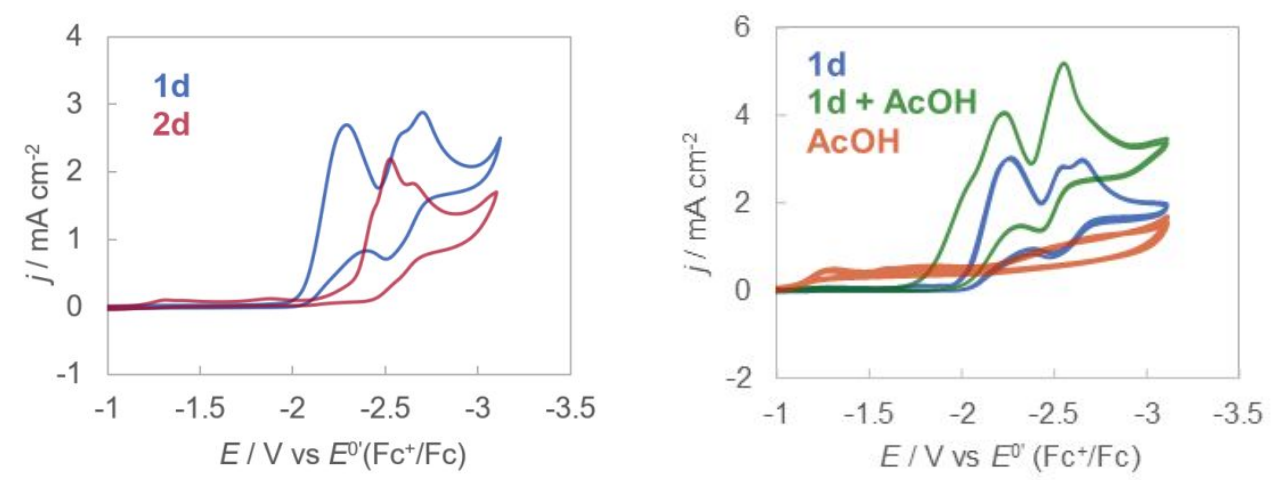

Figure S6. Cyclic voltammograms for reduction of $10 \mathrm{mM} \mathbf{1 d}$ and $\mathbf{2 d}$ with $0.1 \mathrm{M} \mathrm{NBu}_{4} \mathrm{Br}$ in degassed MeCN at 0.1 $\mathrm{Vs}^{-1}$ (left). Cyclic voltammograms for reduction of $10 \mathrm{mM} \mathbf{1 d}$ and $10 \mathrm{mM} \mathrm{AcOH}$ with $0.1 \mathrm{M} \mathrm{NBu}_{4} \mathrm{Br}$ in degassed $\mathrm{MeCN}$ at $0.1 \mathrm{Vs}^{-1}$ (right). 


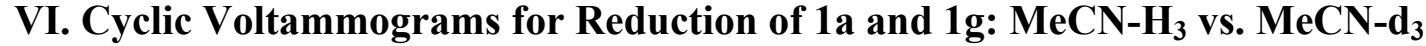

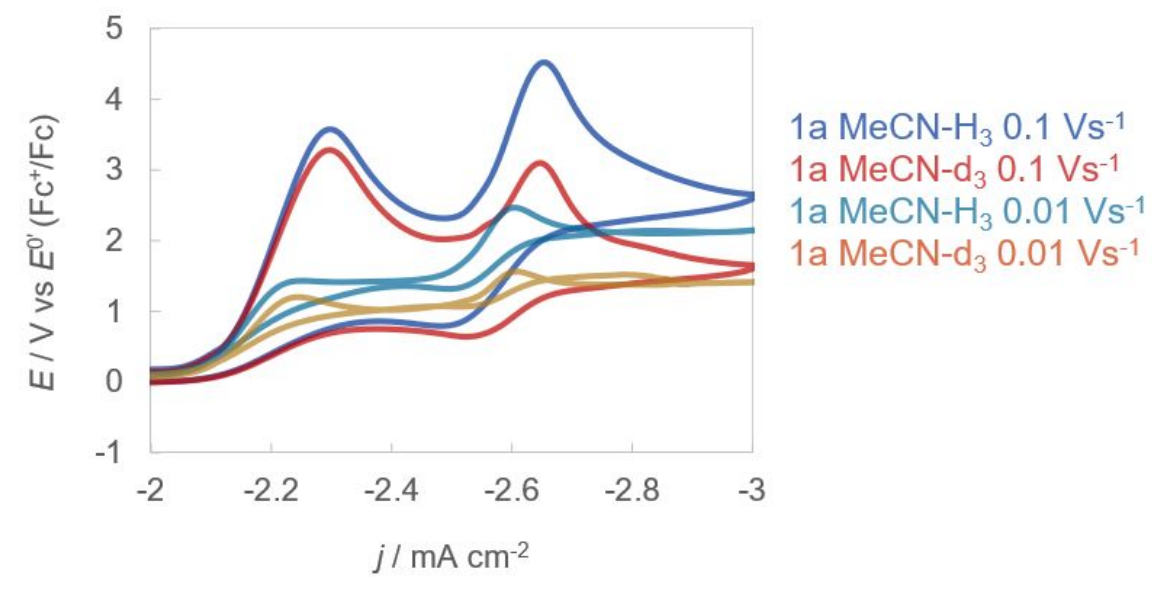

Figure S7. Cyclic voltammograms for reduction of $10 \mathrm{mM} 1 \mathrm{a}$ with $0.1 \mathrm{M} \mathrm{NBu}{ }_{4} \mathrm{Br}$ in degassed $\mathrm{MeCN}-\mathrm{H}_{3}$ or $\mathrm{MeCN}-\mathrm{d}_{3}$ at $0.1 \mathrm{Vs}^{-1}$ or $0.01 \mathrm{Vs}^{-1}$.

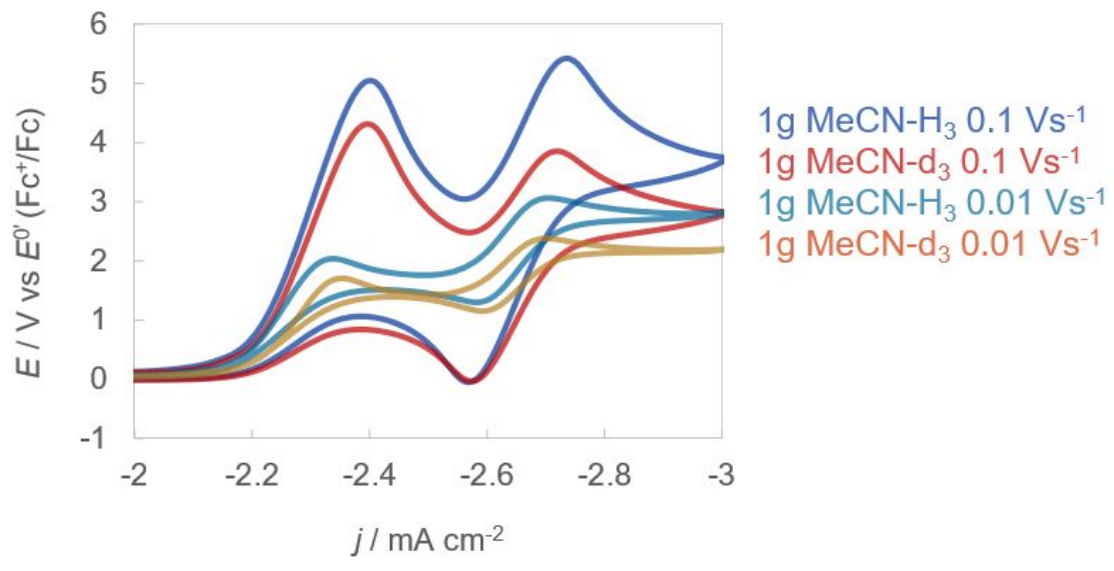

Figure S8. Cyclic voltammograms for reduction of $10 \mathrm{mM} 1 \mathrm{~g}$ with $0.1 \mathrm{M} \mathrm{NBu}_{4} \mathrm{Br}$ in degassed $\mathrm{MeCN}-\mathrm{H}_{3}$ or $\mathrm{MeCN}^{-\mathrm{d}_{3}}$ at $0.1 \mathrm{Vs}^{-1}$ or $0.01 \mathrm{Vs}^{-1}$. 

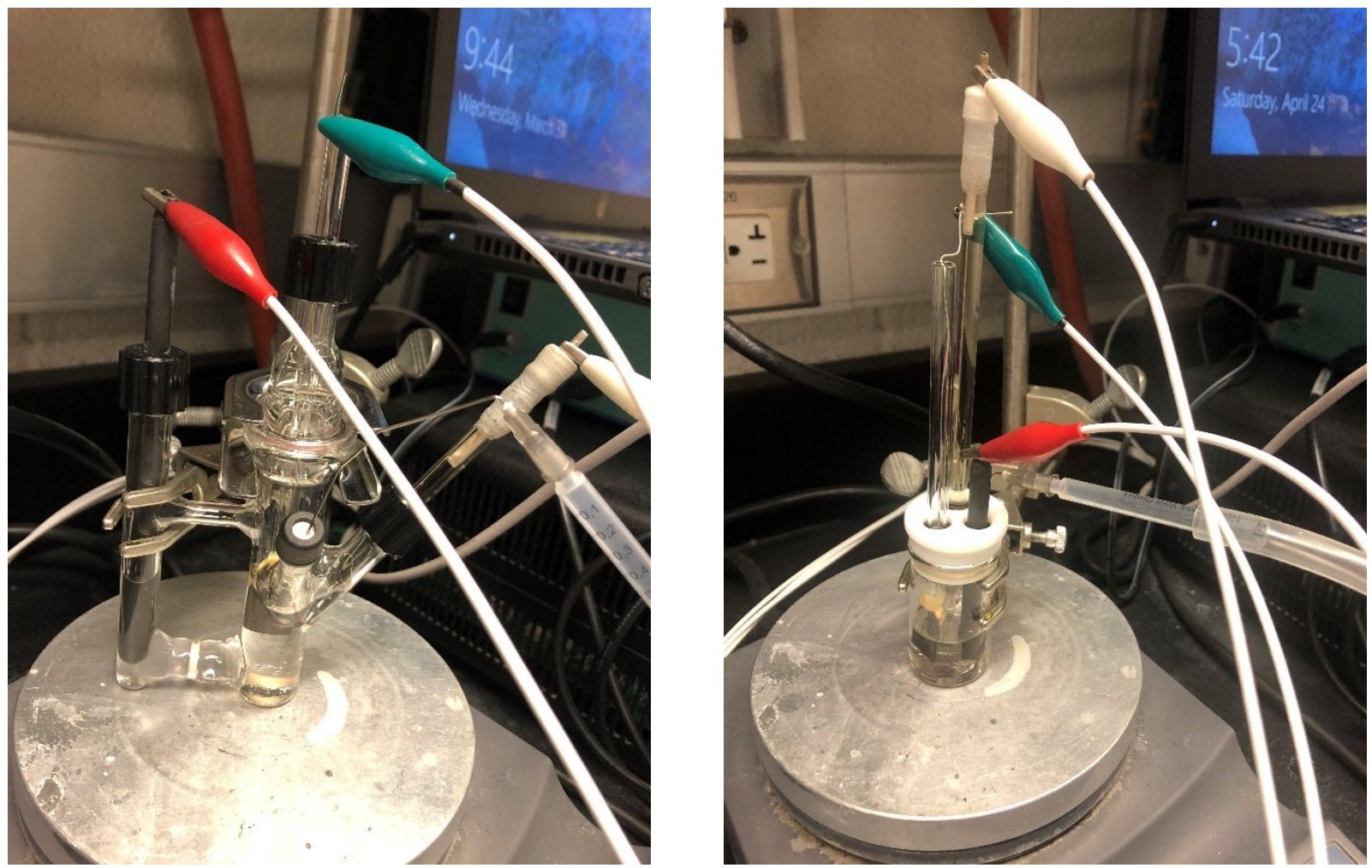

Figure S9. Reaction setup, divided electrolysis (left) and undivided cell (right).

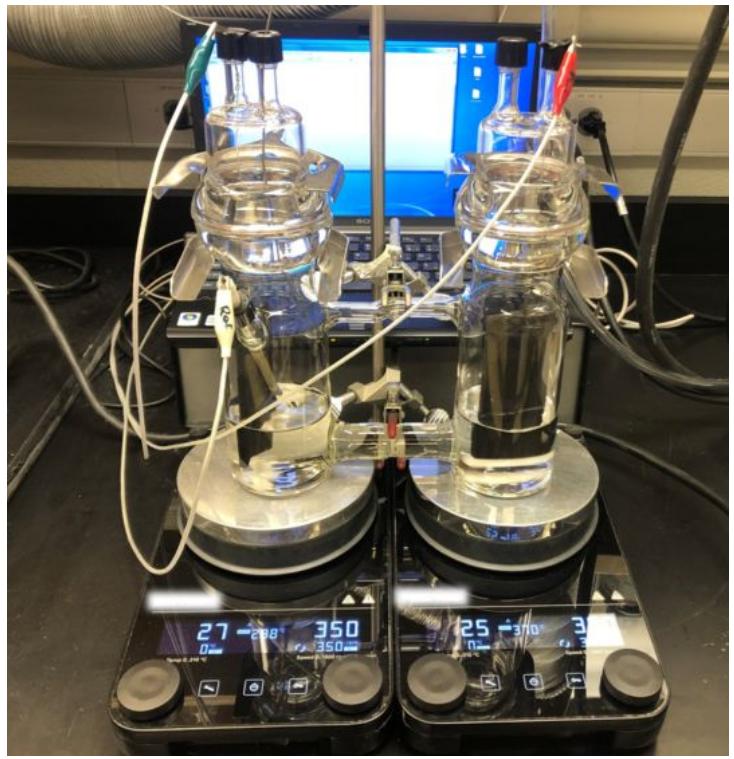

Figure S10. One-gram scale reaction setup. 
VIII. ${ }^{1} \mathrm{H}$ NMR and ${ }^{13} \mathrm{C}$ NMR Spectra of Products $2 \mathrm{a}-2 \mathrm{~h}, 3 \mathrm{a}-3 \mathrm{~b}$ and $4 \mathrm{a}-4 \mathrm{f}$

ले ने ने ने

ベ

6

เก

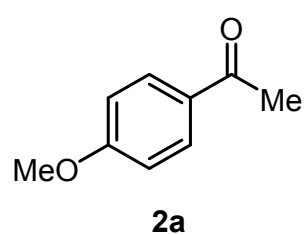

${ }^{1} \mathrm{H} \mathrm{NMR}\left(500 \mathrm{MHz}, \mathrm{CDCl}_{3}\right)$
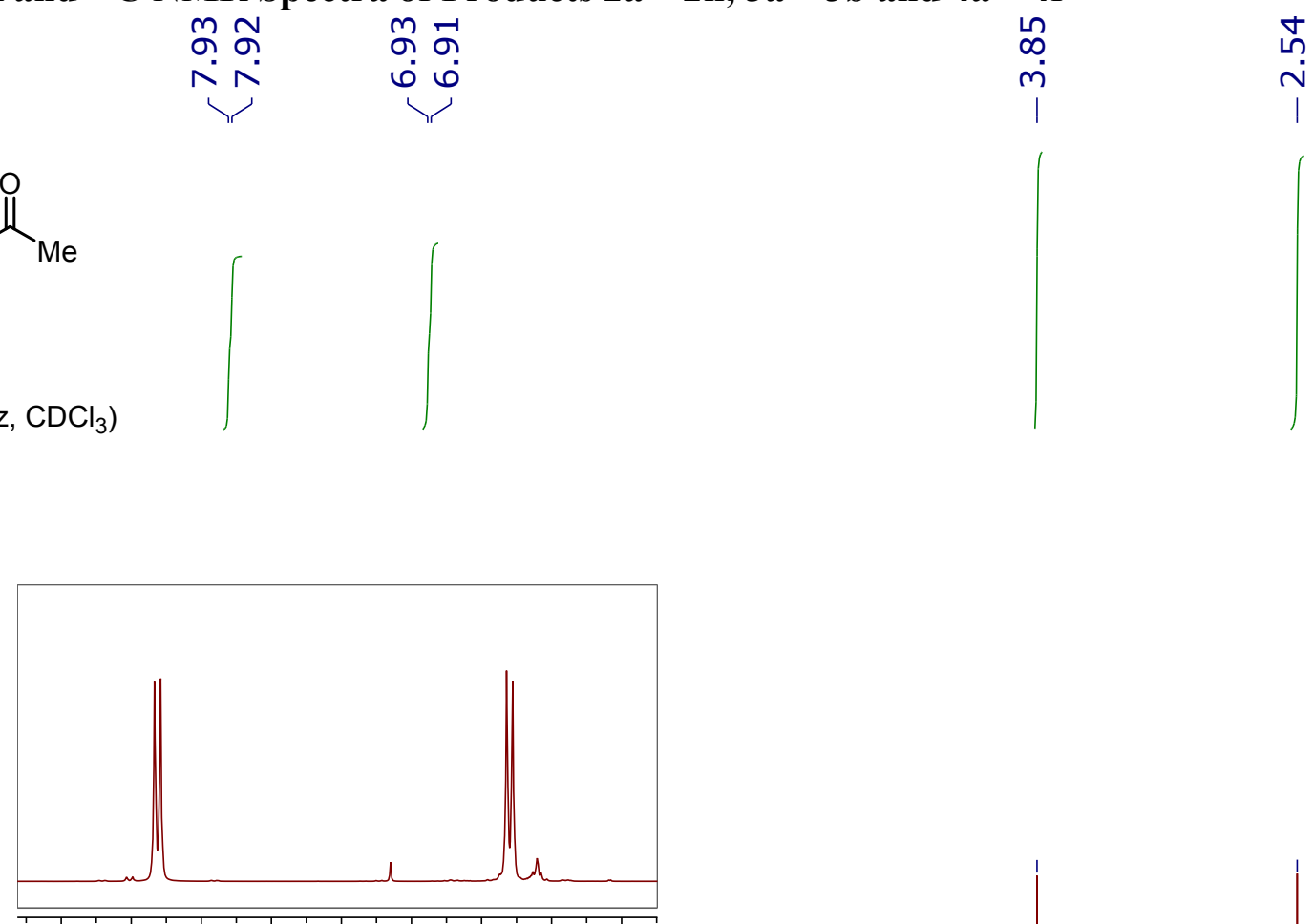

8.28 .07 .87 .67 .47 .27 .06 .86 .6

f1 (ppm)

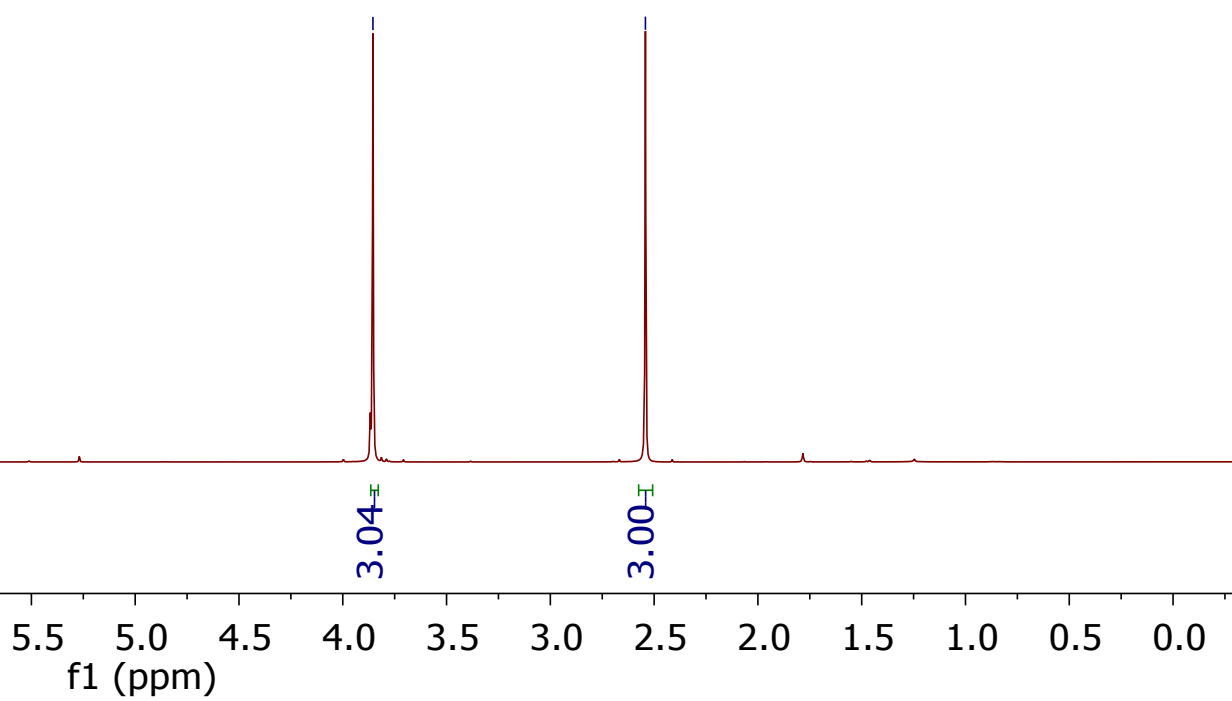




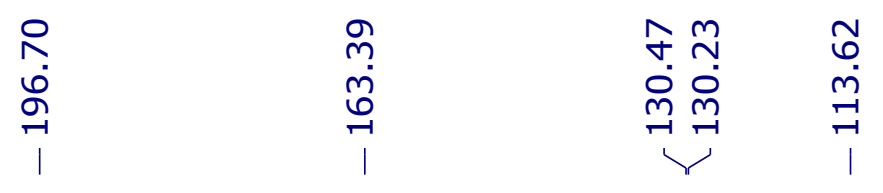

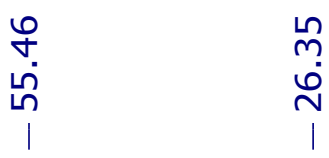

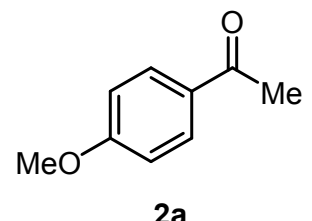

${ }^{13} \mathrm{C}\left\{{ }^{1} \mathrm{H}\right\}$ NMR (126 MHz, $\left.\mathrm{CDCl}_{3}\right)$

$\begin{array}{lllllllllllll}220 & 210 & 200 & 190 & 180 & 170 & 160 & 150 & 140 & 130 & 120 & 110 & 100\end{array}$ 


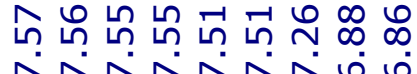

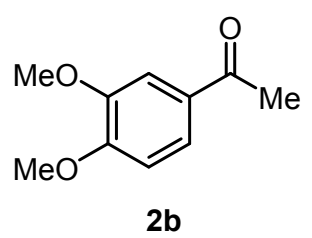

${ }^{1} \mathrm{H}$ NMR $\left(500 \mathrm{MHz}, \mathrm{CDCl}_{3}\right)$
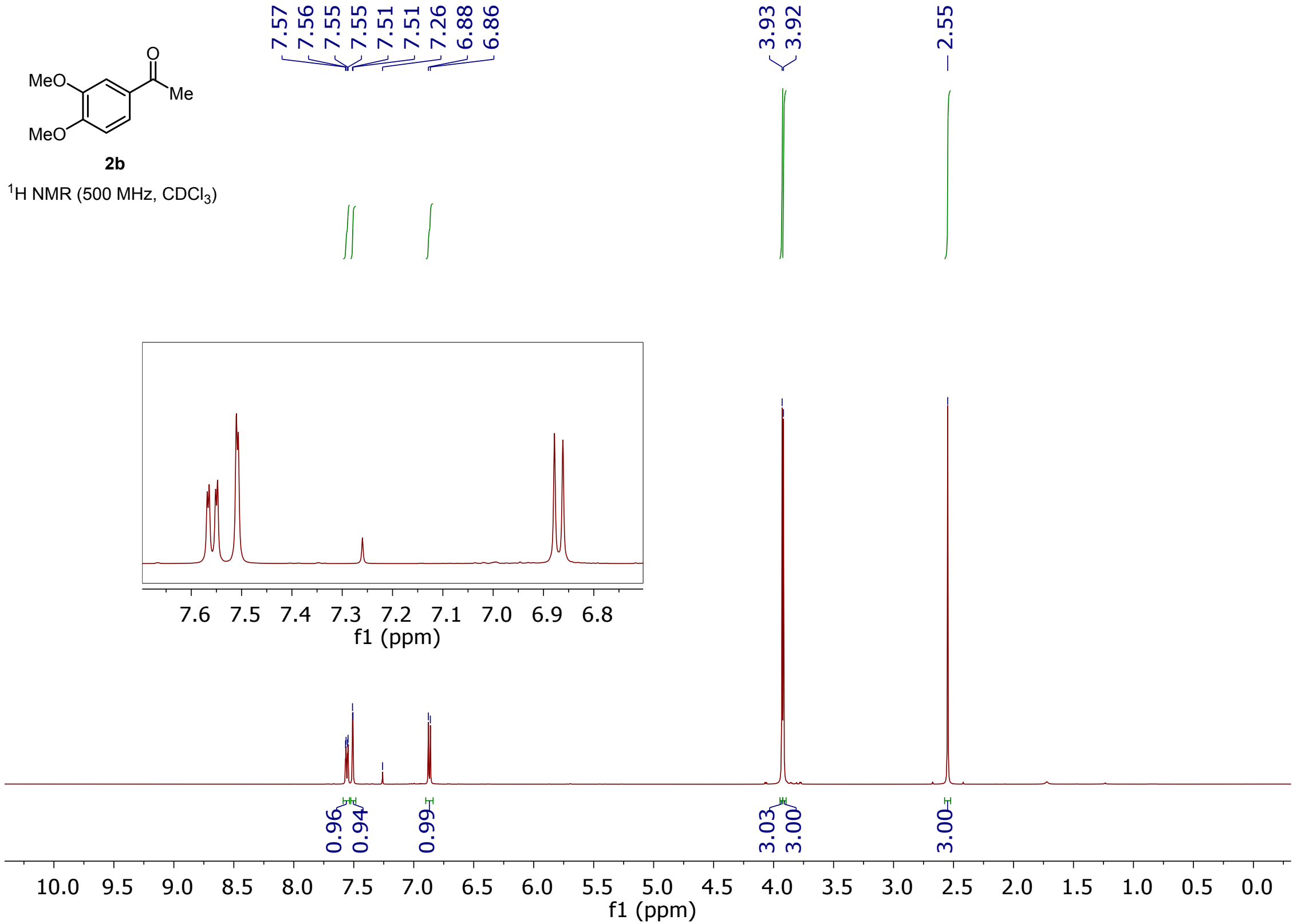


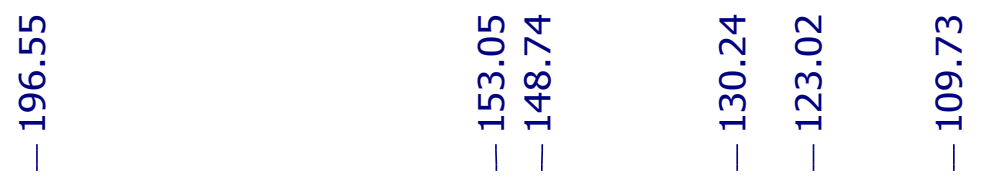

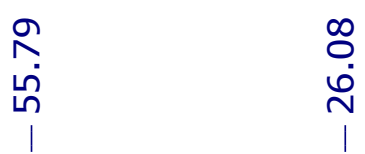

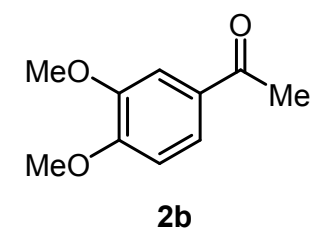

${ }^{13} \mathrm{C}\left\{{ }^{1} \mathrm{H}\right\}$ NMR (126 MHz, $\left.\mathrm{CDCl}_{3}\right)$

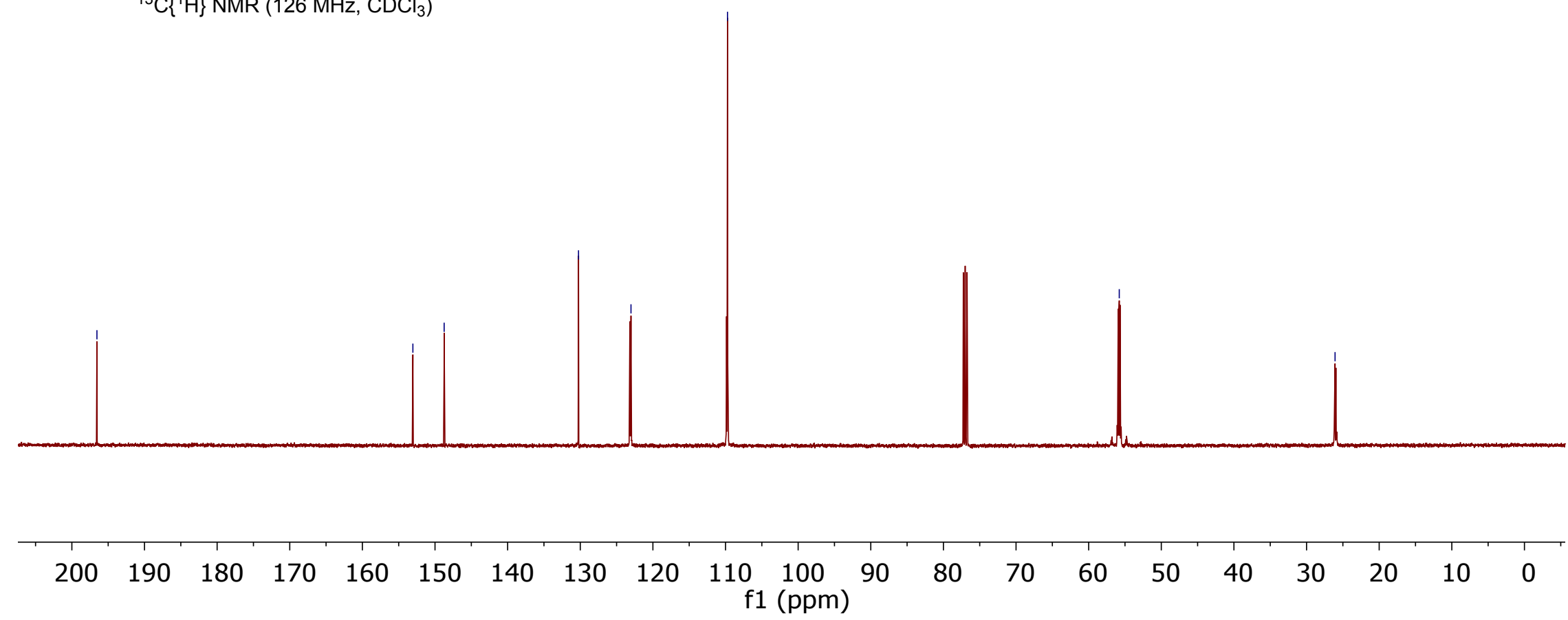



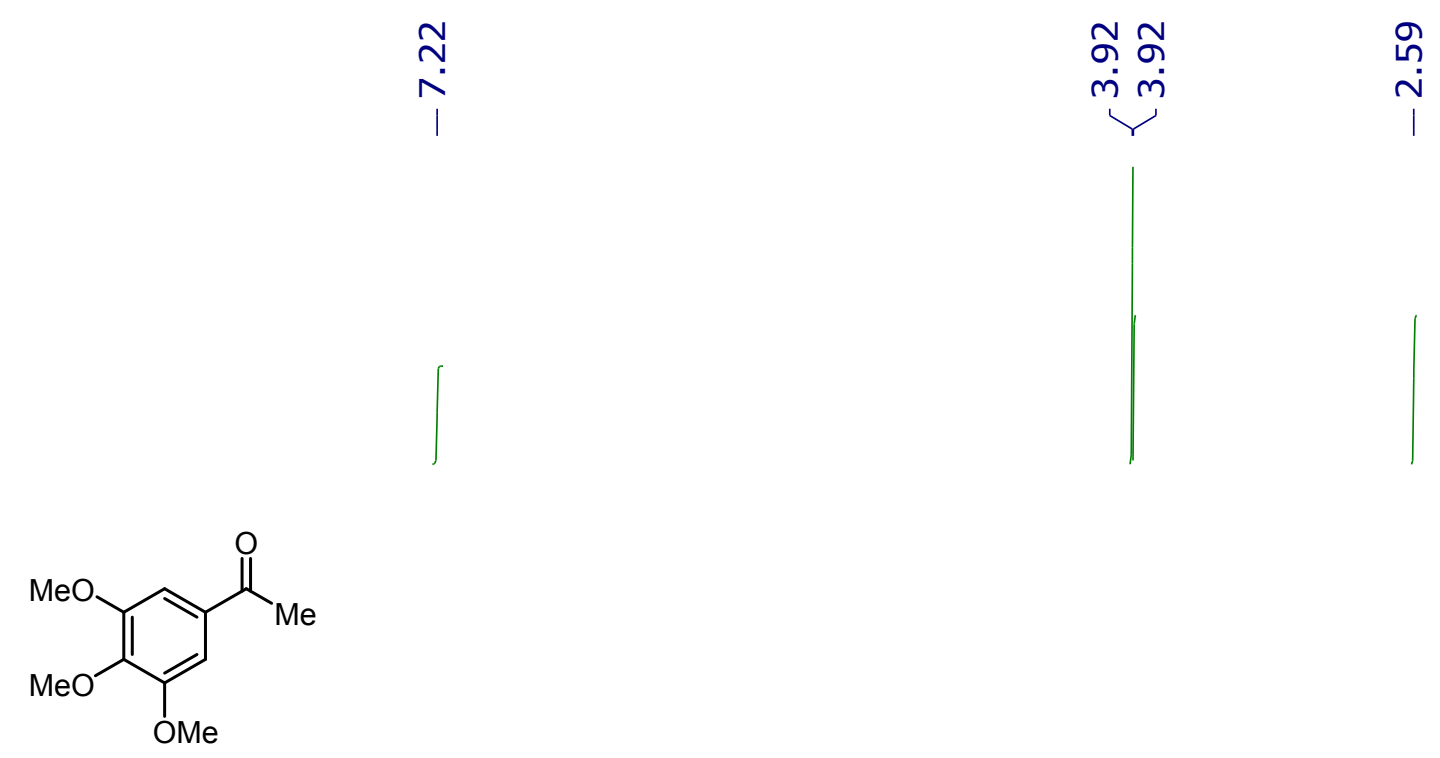

2c

${ }^{1} \mathrm{H}$ NMR $\left(500 \mathrm{MHz}, \mathrm{CDCl}_{3}\right)$

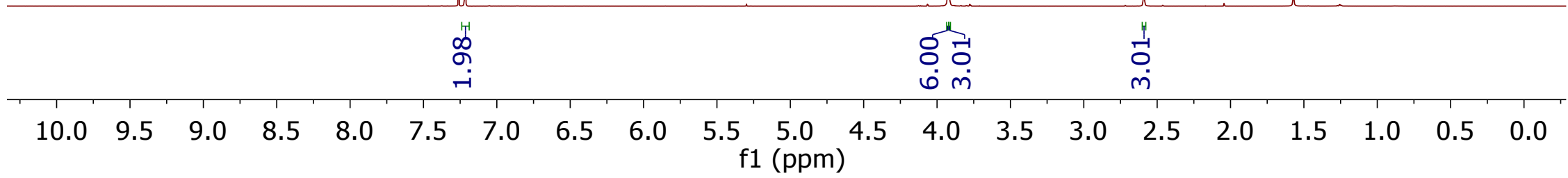




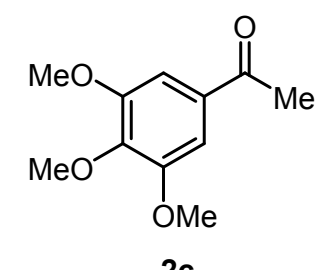

${ }^{13} \mathrm{C}\left\{{ }^{1} \mathrm{H}\right\}$ NMR (126 MHz, $\left.\mathrm{CDCl}_{3}\right)$

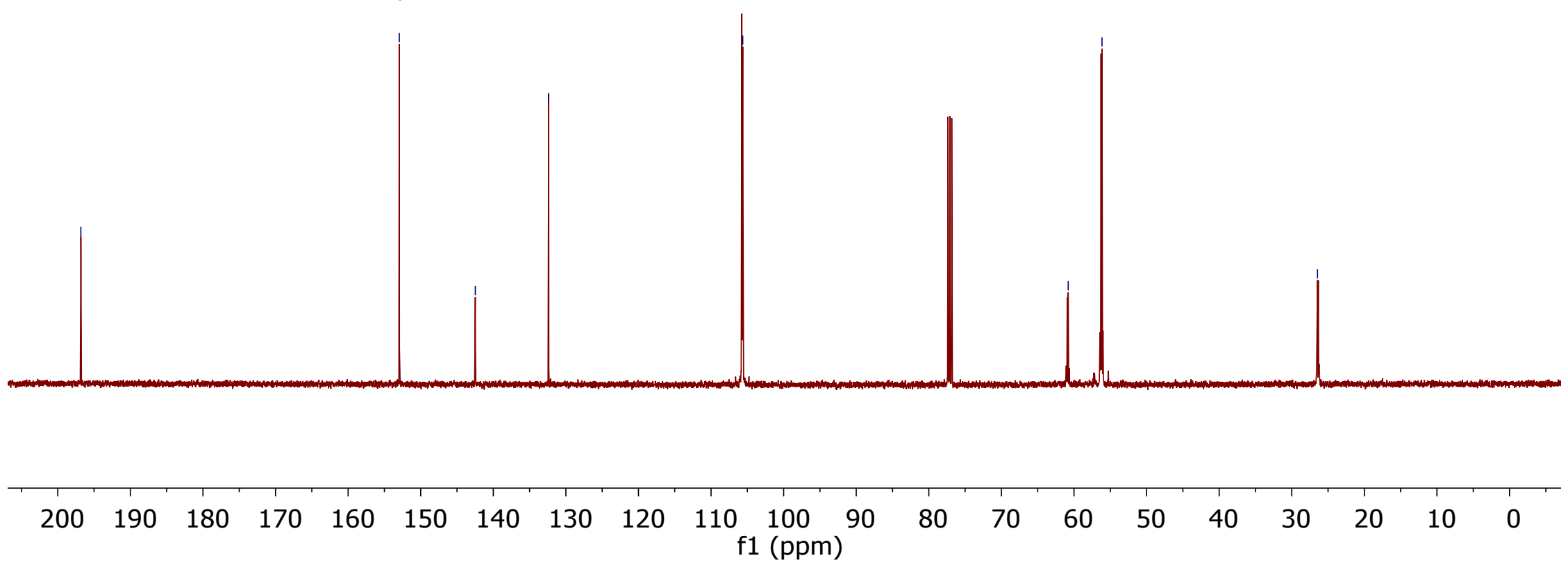



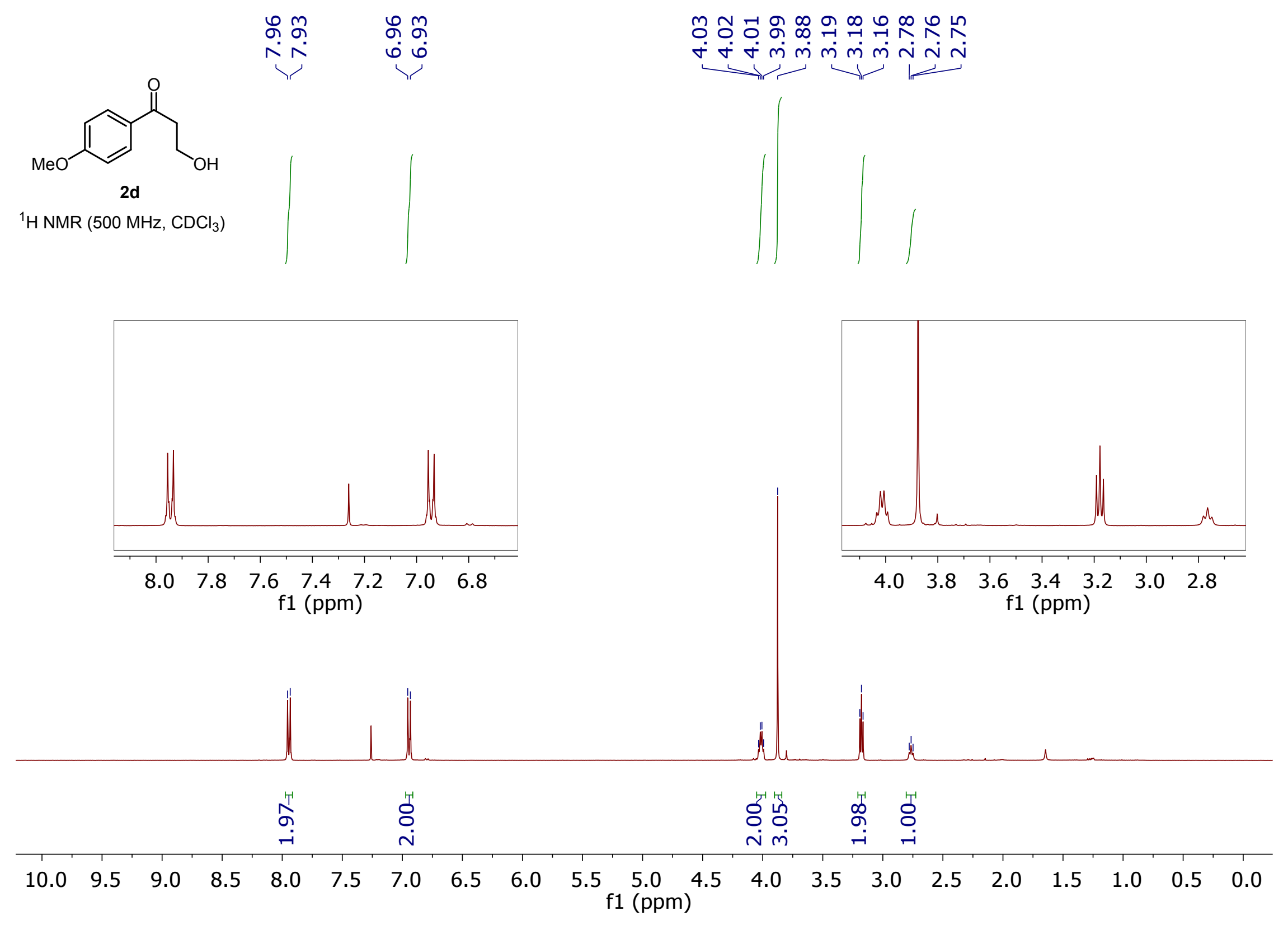

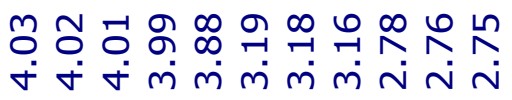
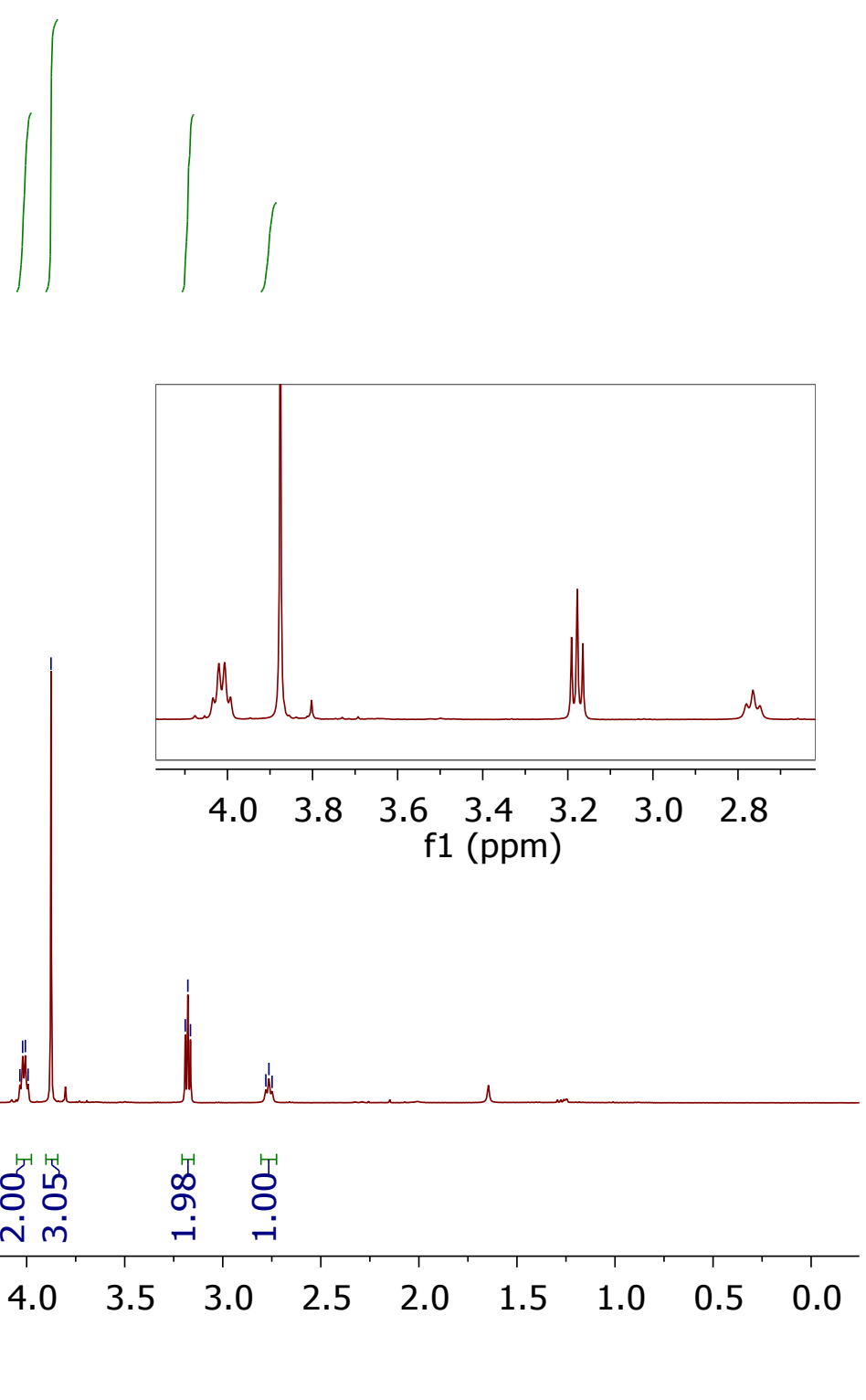


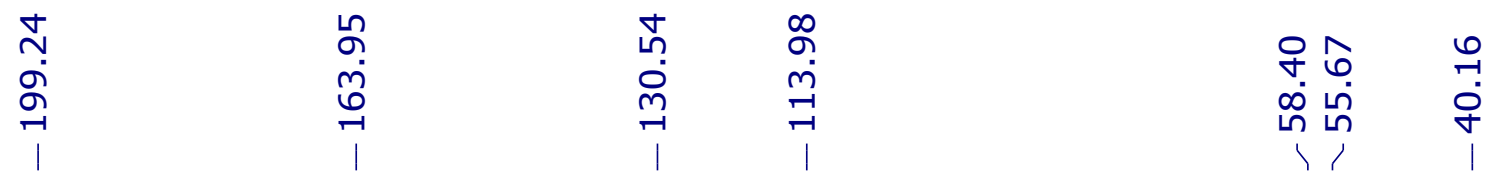

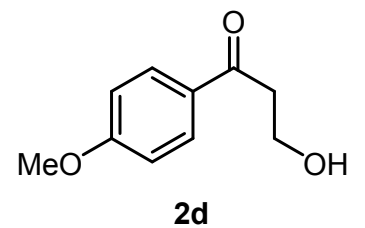

${ }^{13} \mathrm{C}\left\{{ }^{1} \mathrm{H}\right\} \mathrm{NMR}\left(126 \mathrm{MHz}, \mathrm{CDCl}_{3}\right)$

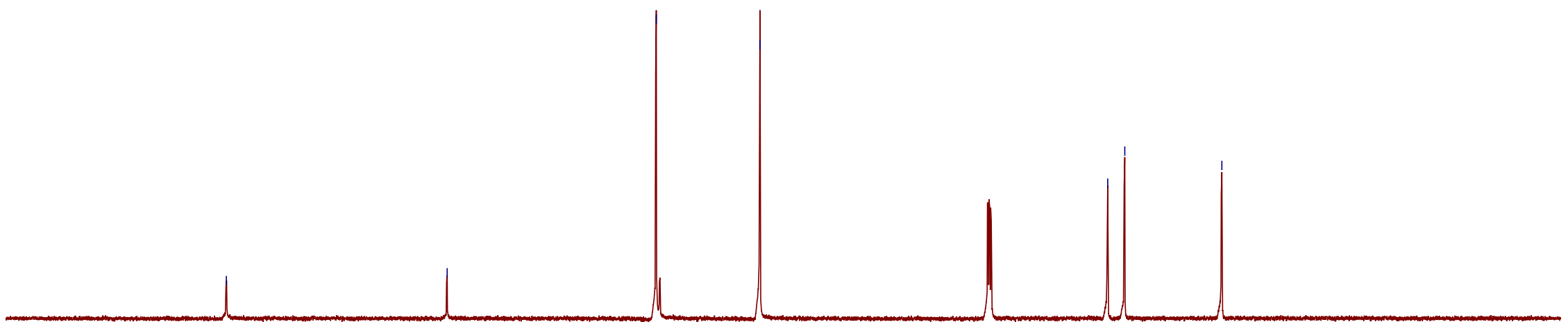

$\begin{array}{llllllllllllllllllllllllll}230 & 220 & 210 & 200 & 190 & 180 & 170 & 160 & 150 & 140 & 130 & 120 & 110 & 100 & 90 & 80 & 70 & 60 & 50 & 40 & 30 & 20 & 10 & 0 & -10\end{array}$ f1 (ppm) 


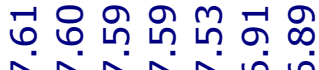

ヘヘNヘヘ

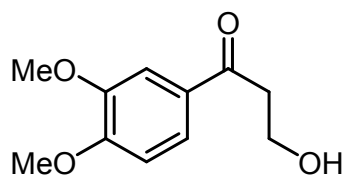

$2 e$

${ }^{1} \mathrm{H}$ NMR $\left(500 \mathrm{MHz}, \mathrm{CDCl}_{3}\right)$
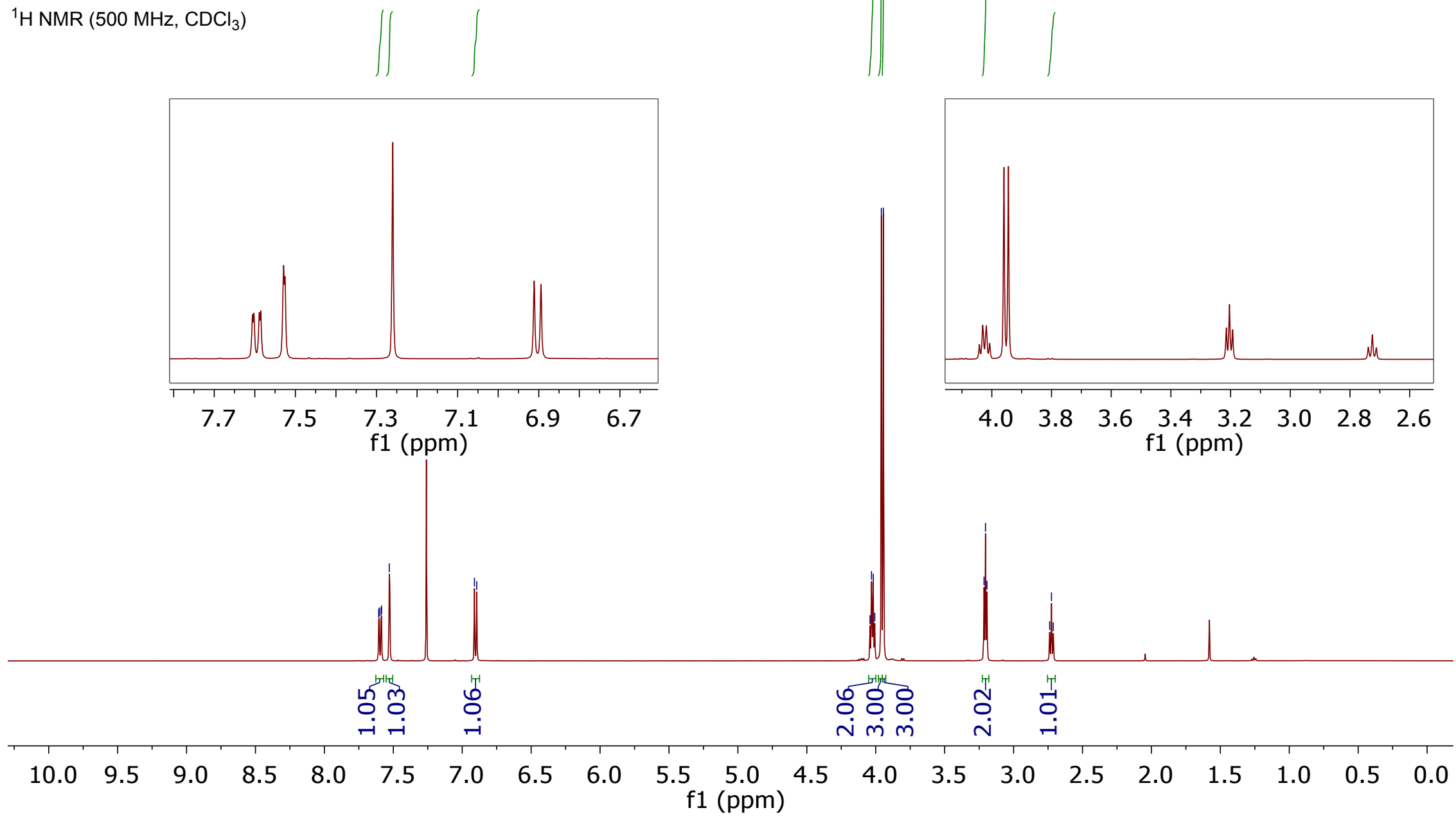

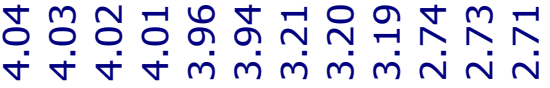
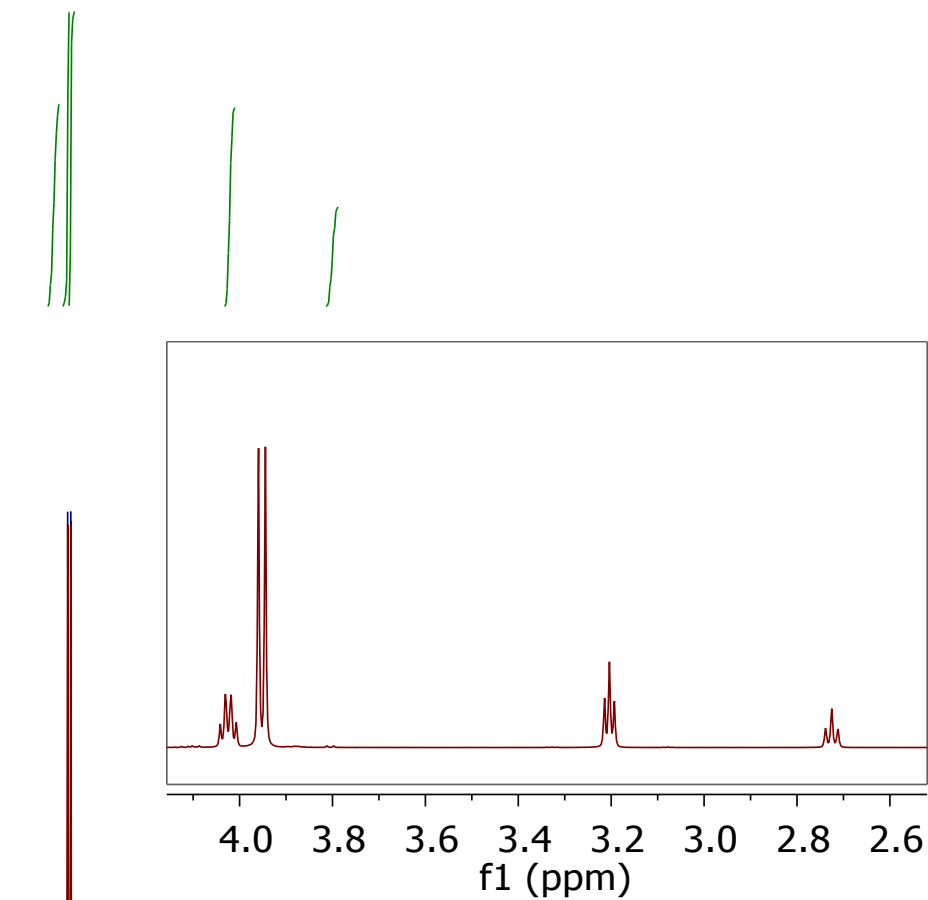


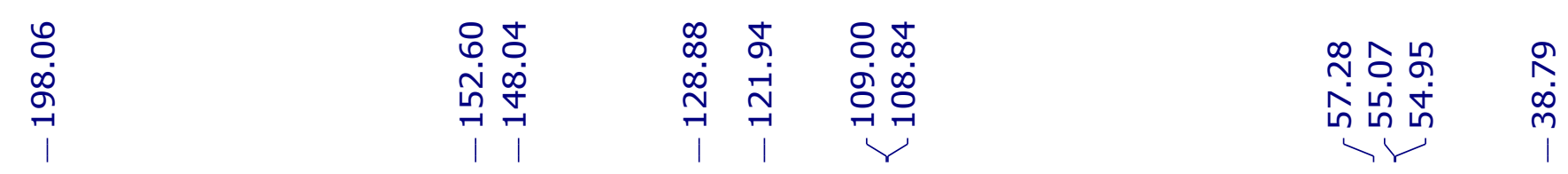

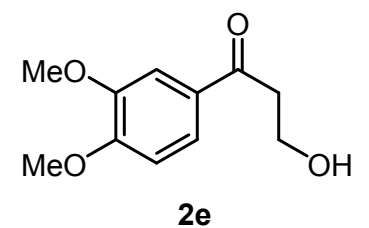

${ }^{13} \mathrm{C}\left\{{ }^{1} \mathrm{H}\right\}$ NMR $\left(126 \mathrm{MHz}, \mathrm{CDCl}_{3}\right)$
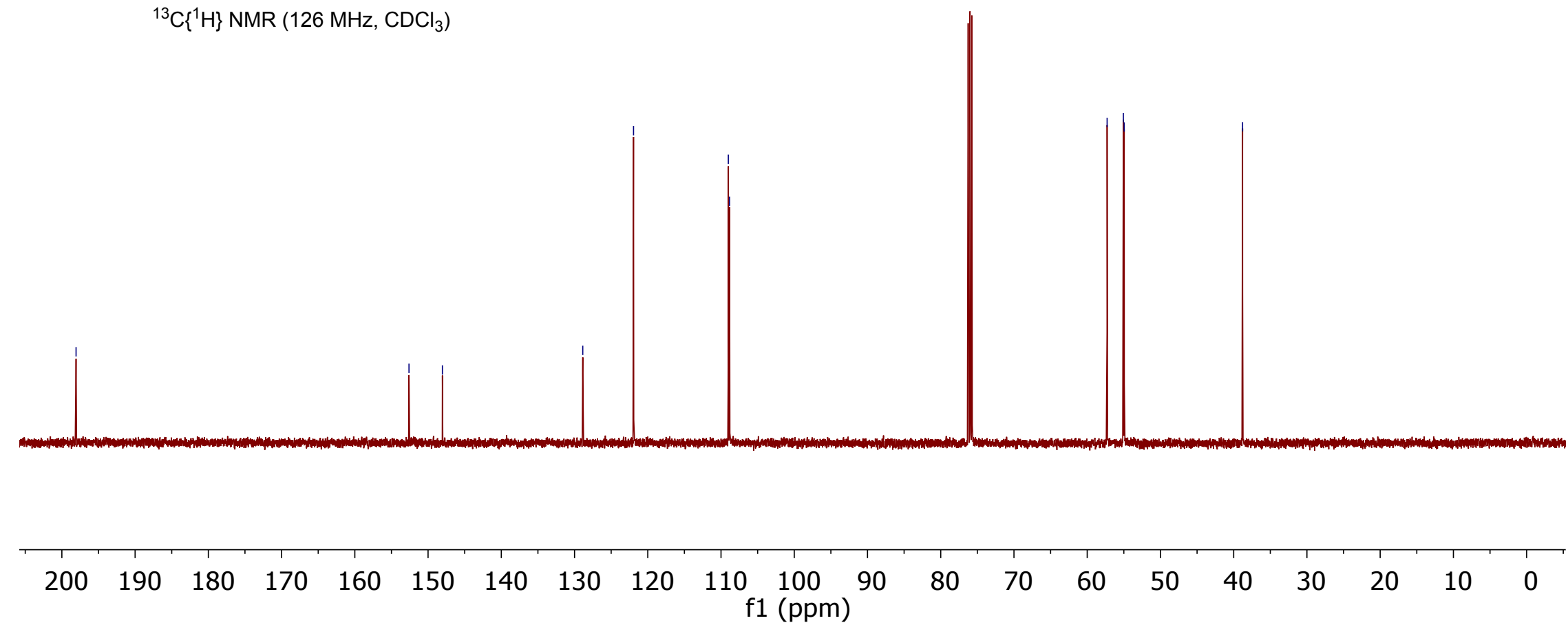


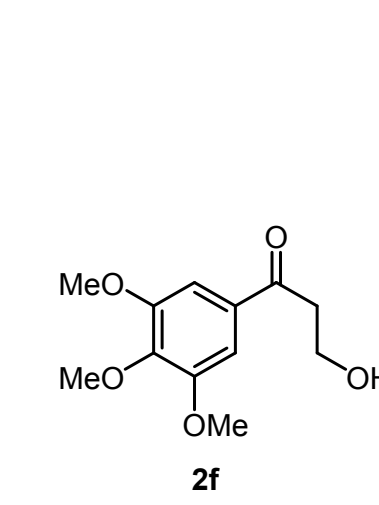

${ }^{1} \mathrm{H}$ NMR $\left(500 \mathrm{MHz}, \mathrm{CDCl}_{3}\right)$

$$
\stackrel{m}{N}
$$

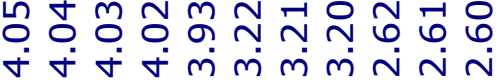
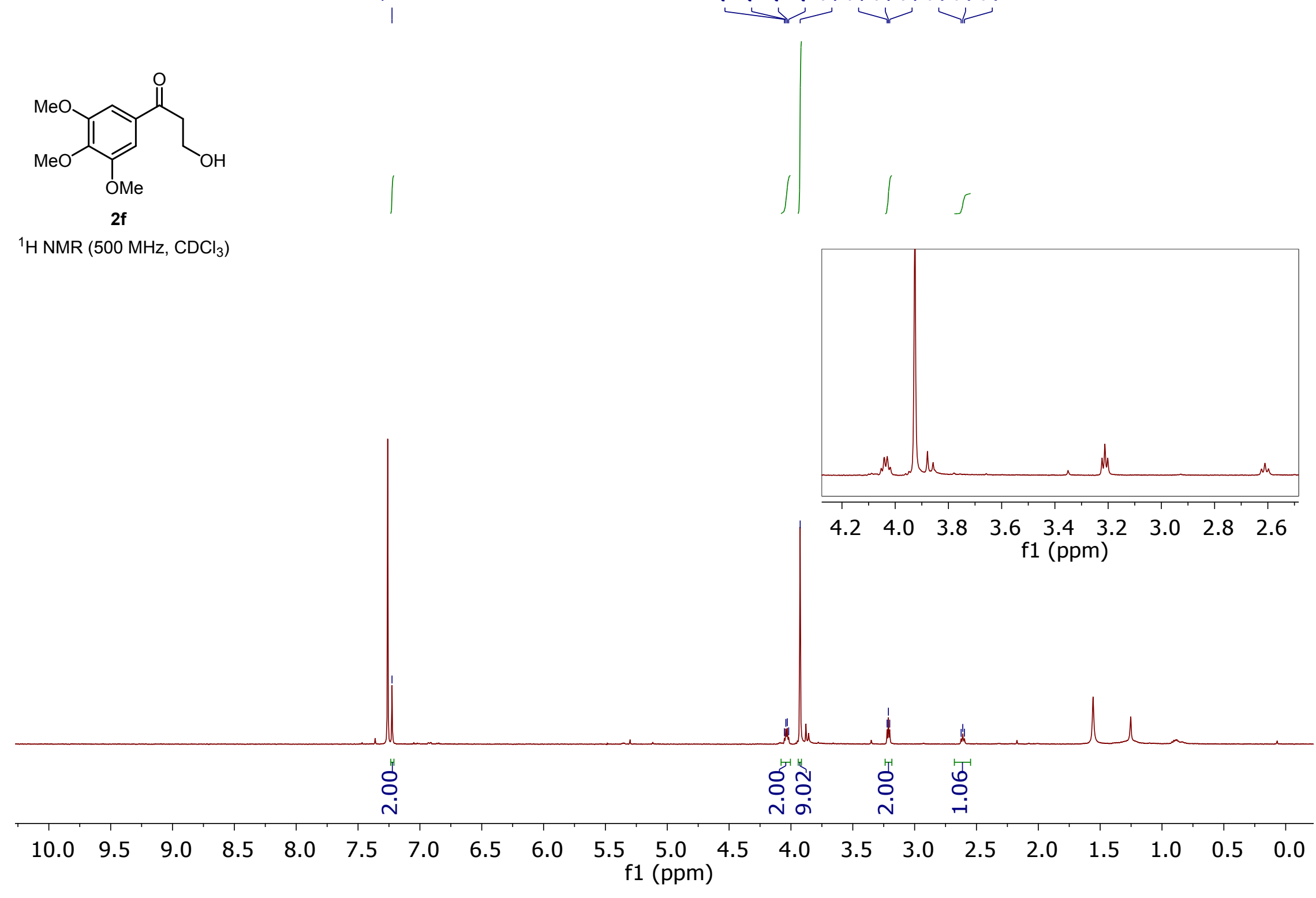


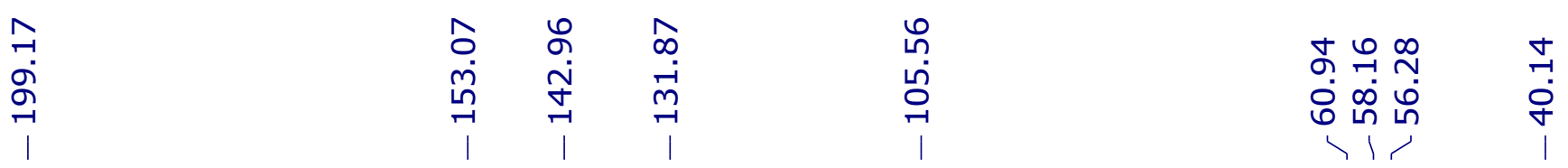

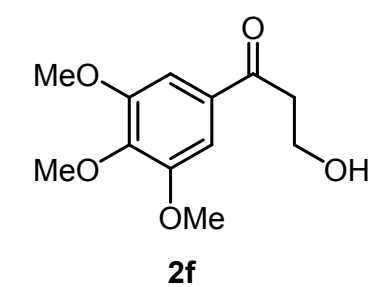

${ }^{13} \mathrm{C}\left\{{ }^{1} \mathrm{H}\right\}$ NMR (126 MHz, $\left.\mathrm{CDCl}_{3}\right)$
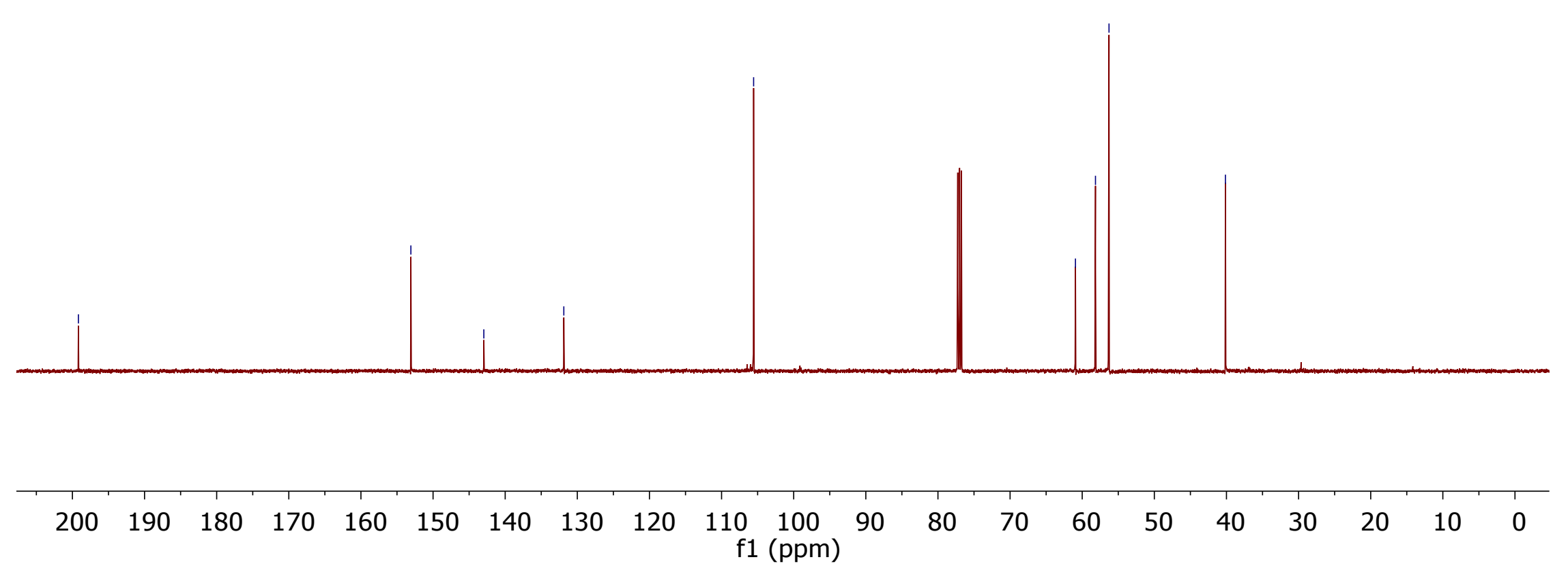

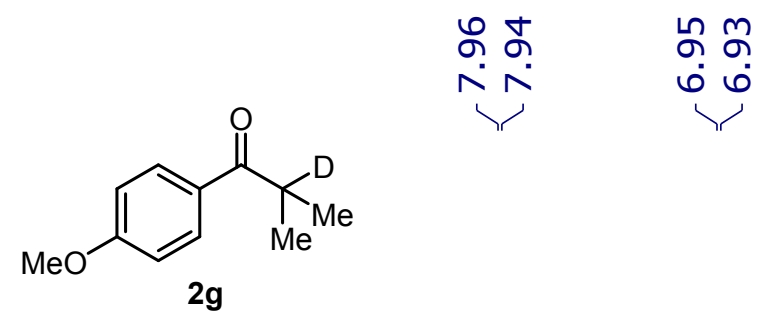

${ }^{1} \mathrm{H}$ NMR $\left(500 \mathrm{MHz}, \mathrm{CDCl}_{3}\right)$
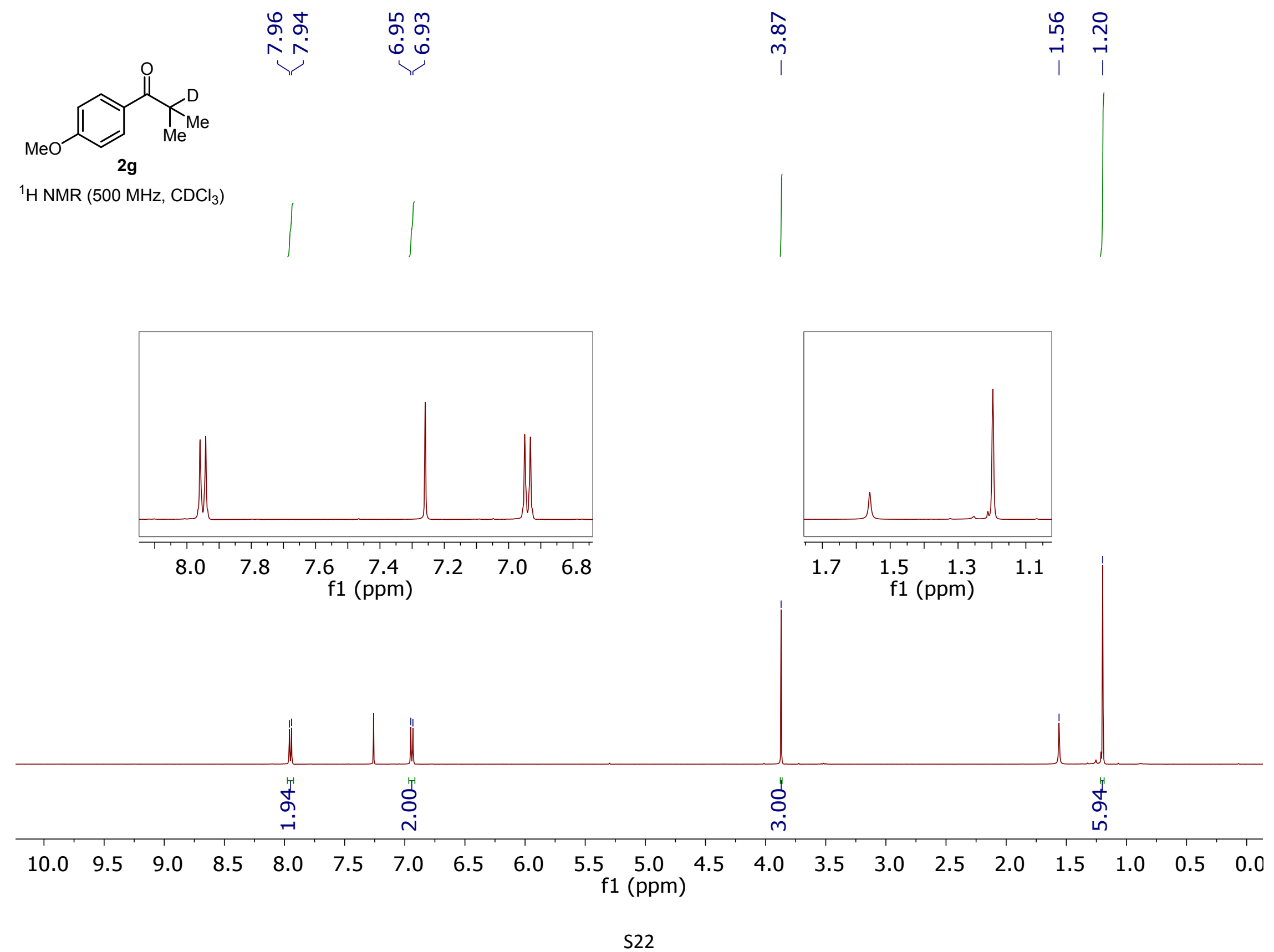


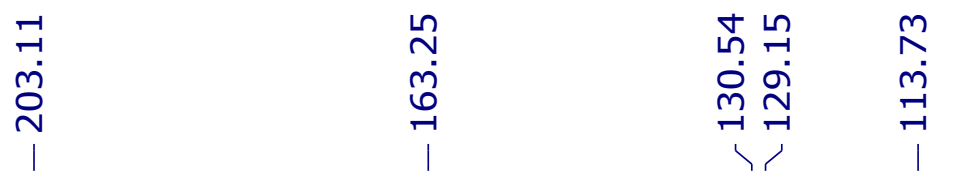

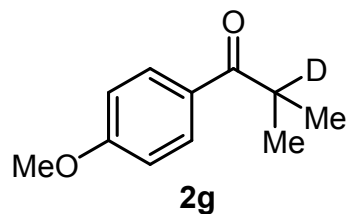

${ }^{13} \mathrm{C}\left\{{ }^{1} \mathrm{H}\right\}$ NMR (126 MHz, $\left.\mathrm{CDCl}_{3}\right)$
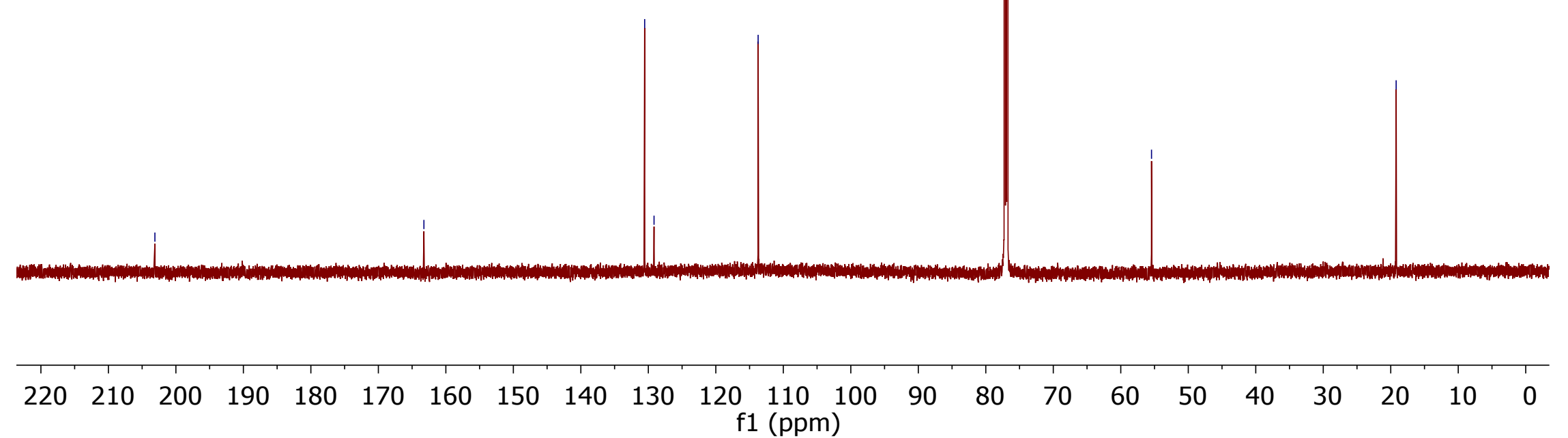


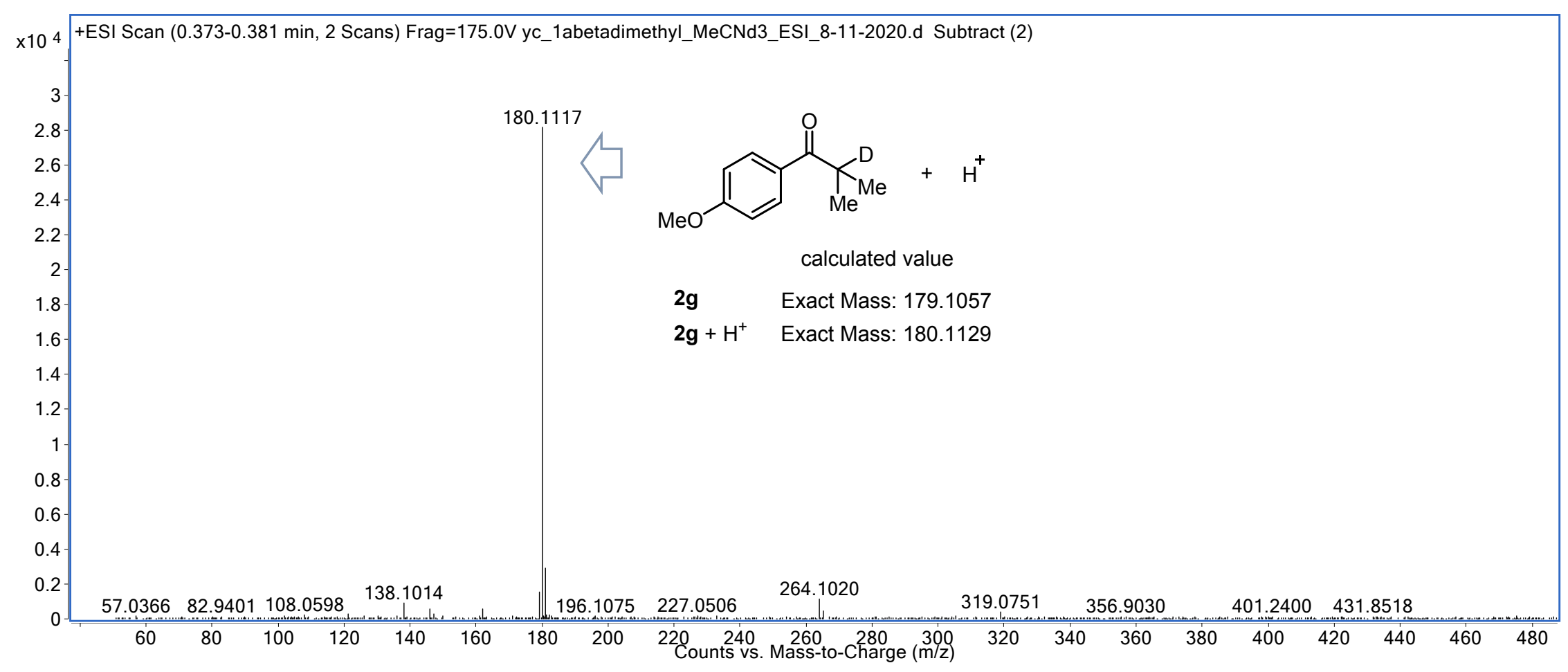




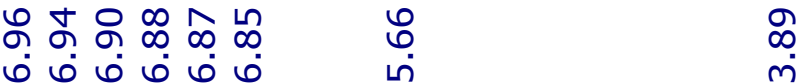

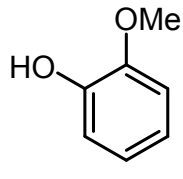

3a

${ }^{1} \mathrm{H}$ NMR $\left(500 \mathrm{MHz}, \mathrm{CDCl}_{3}\right)$
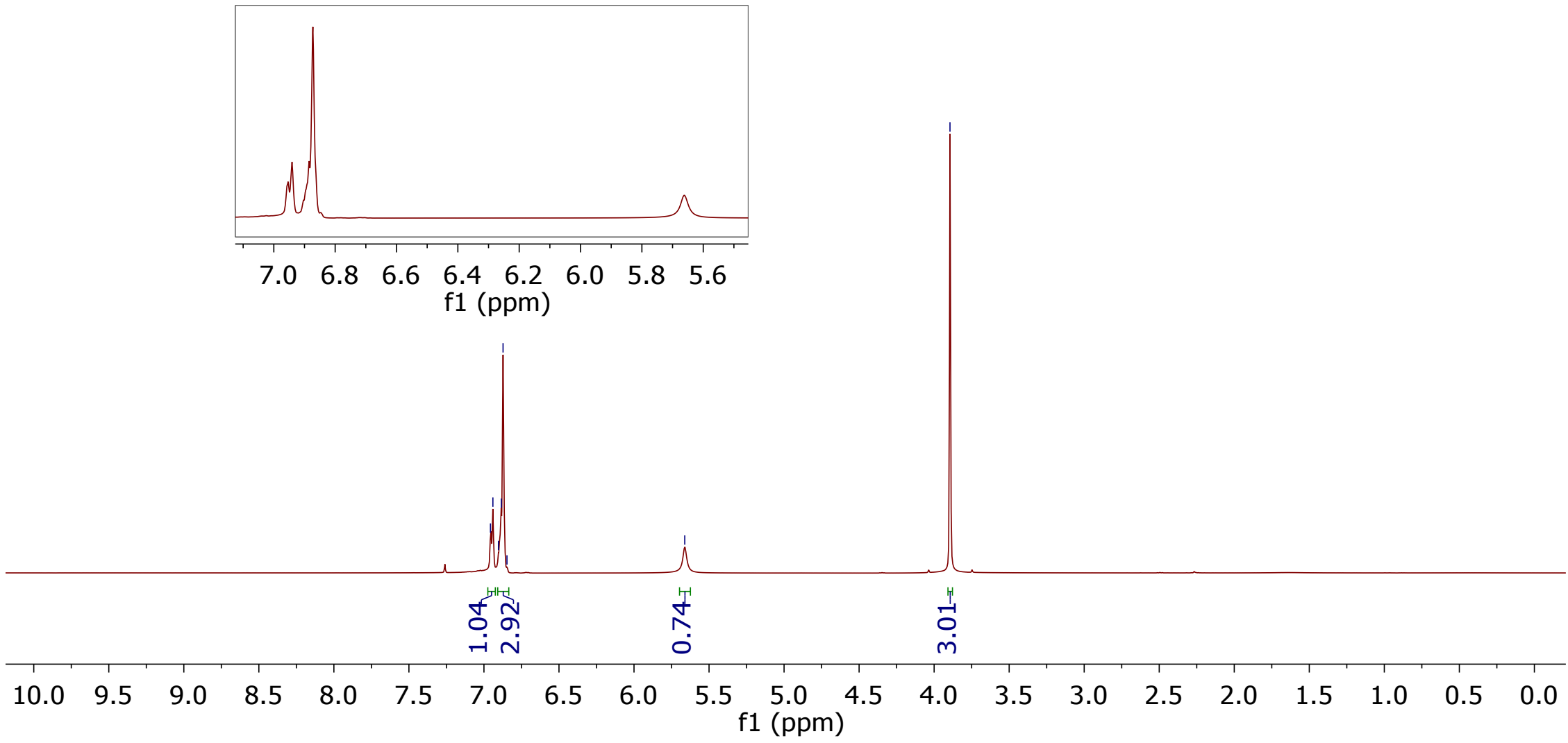


\begin{tabular}{|c|c|}
\hline 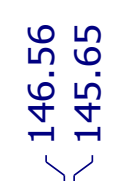 & 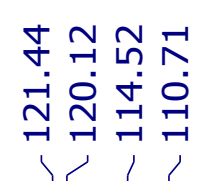 \\
\hline
\end{tabular}

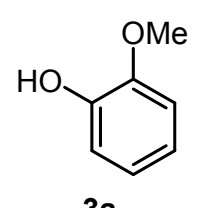

${ }^{13} \mathrm{C}\left\{{ }^{1} \mathrm{H}\right\} \mathrm{NMR}\left(126 \mathrm{MHz}, \mathrm{CDCl}_{3}\right)$
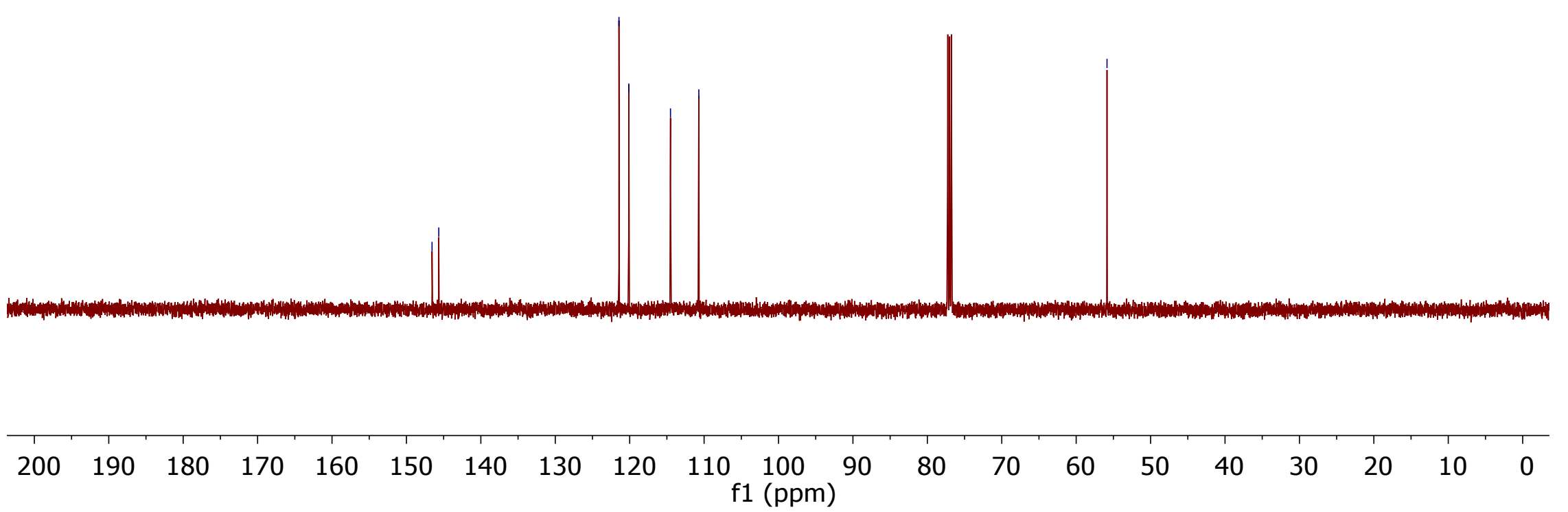


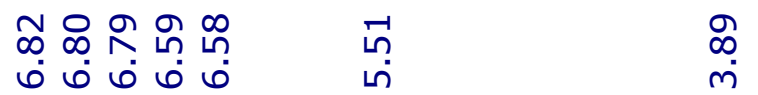

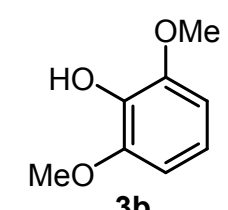

$3 b$

${ }^{1} \mathrm{H} \mathrm{NMR}\left(500 \mathrm{MHz}, \mathrm{CDCl}_{3}\right)$

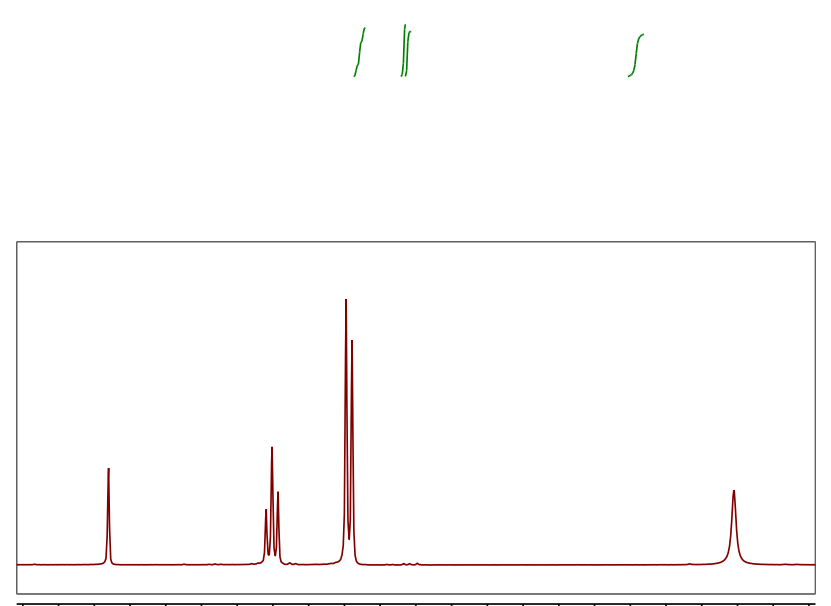

$7.47 .27 .06 .86 .6 \quad 6.46 .26 .05 .85 .65 .4$ $\mathrm{f} 1(\mathrm{ppm})$

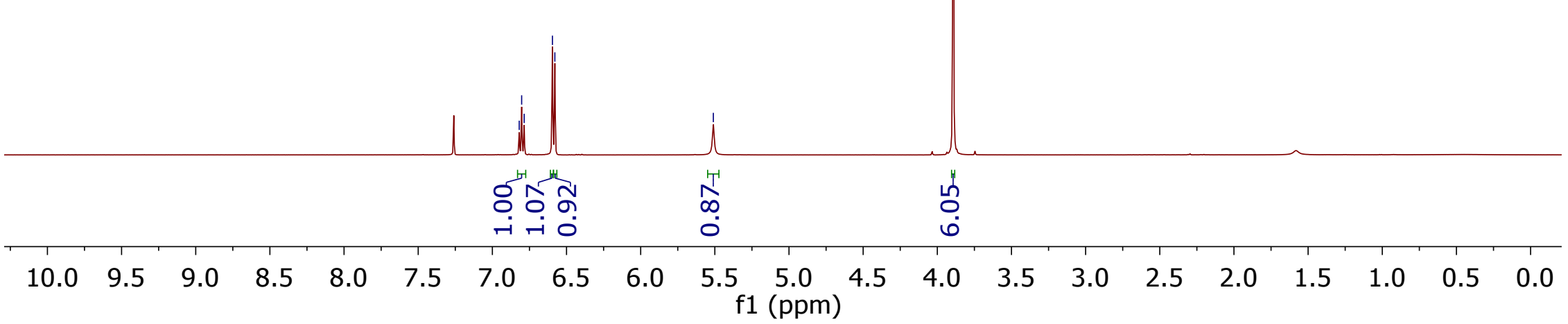




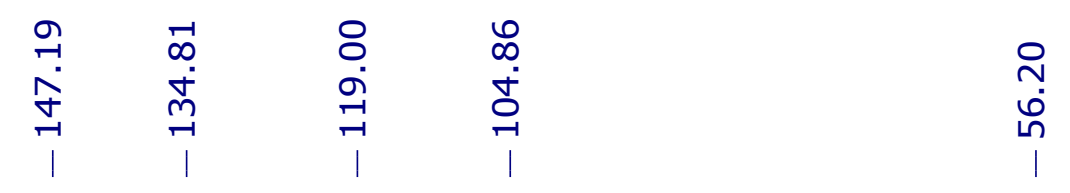

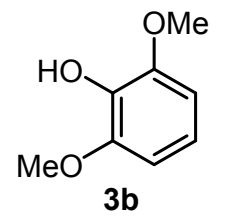

$\left.{ }^{13} \mathrm{C}_{\{}{ }^{1} \mathrm{H}\right\} \mathrm{NMR}\left(126 \mathrm{MHz}, \mathrm{CDCl}_{3}\right)$
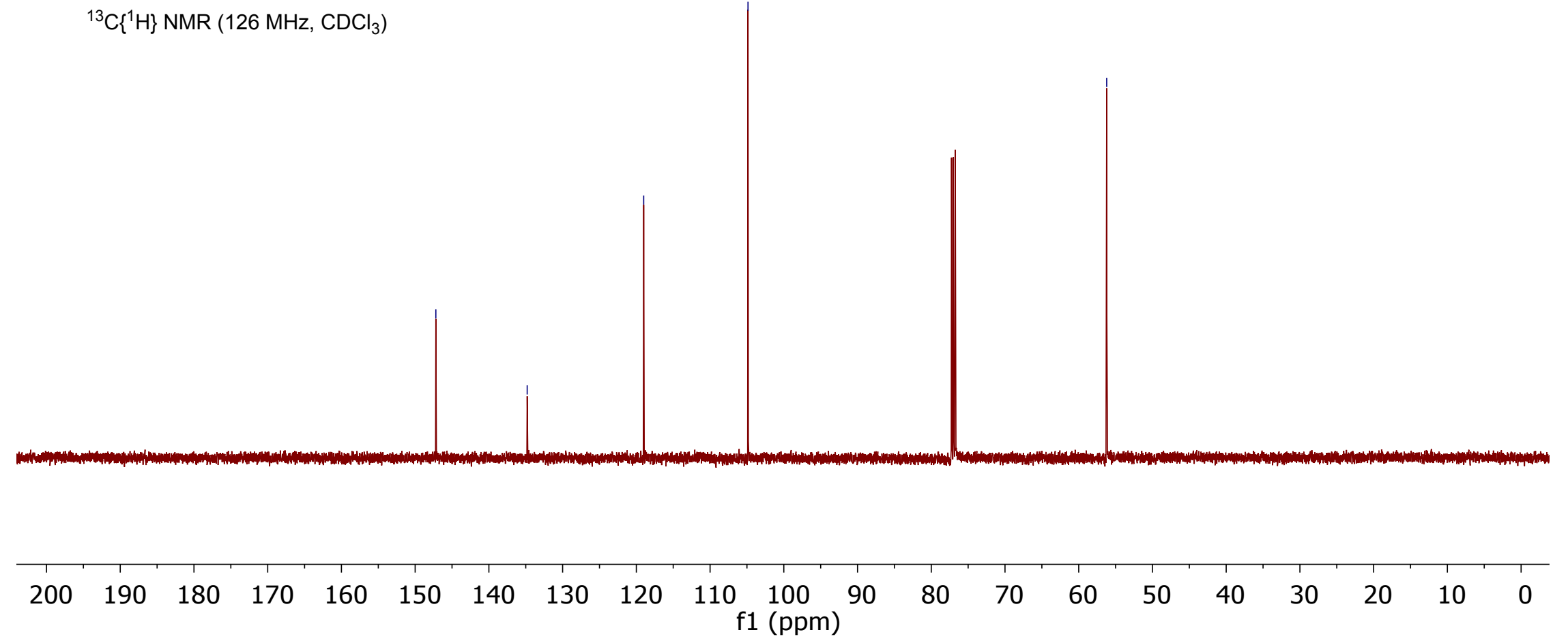


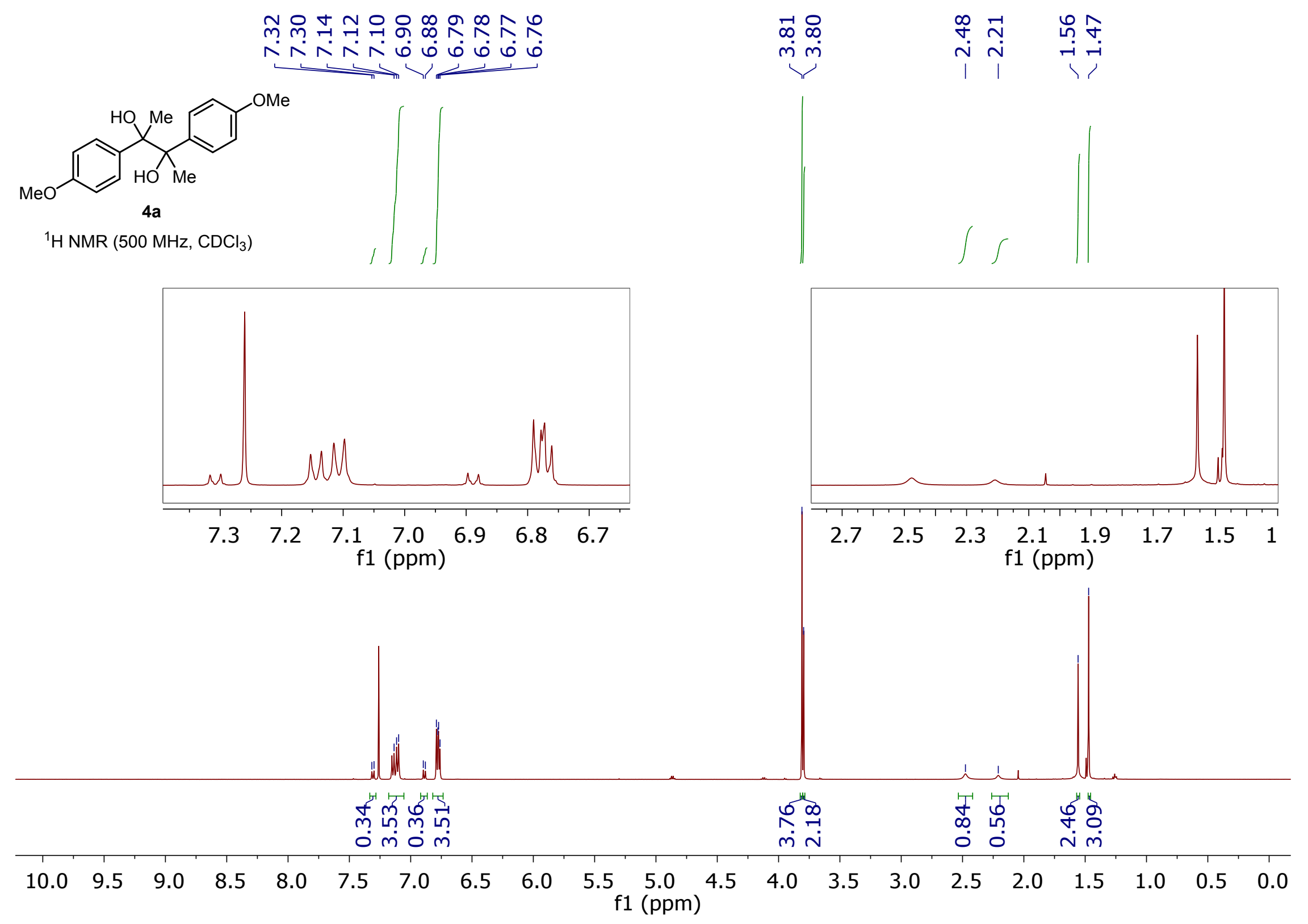




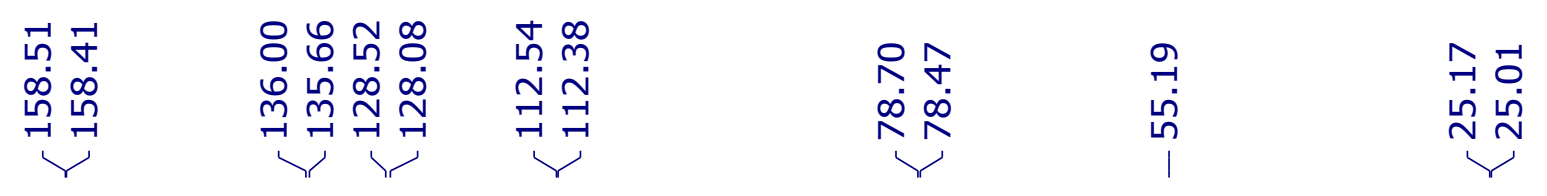
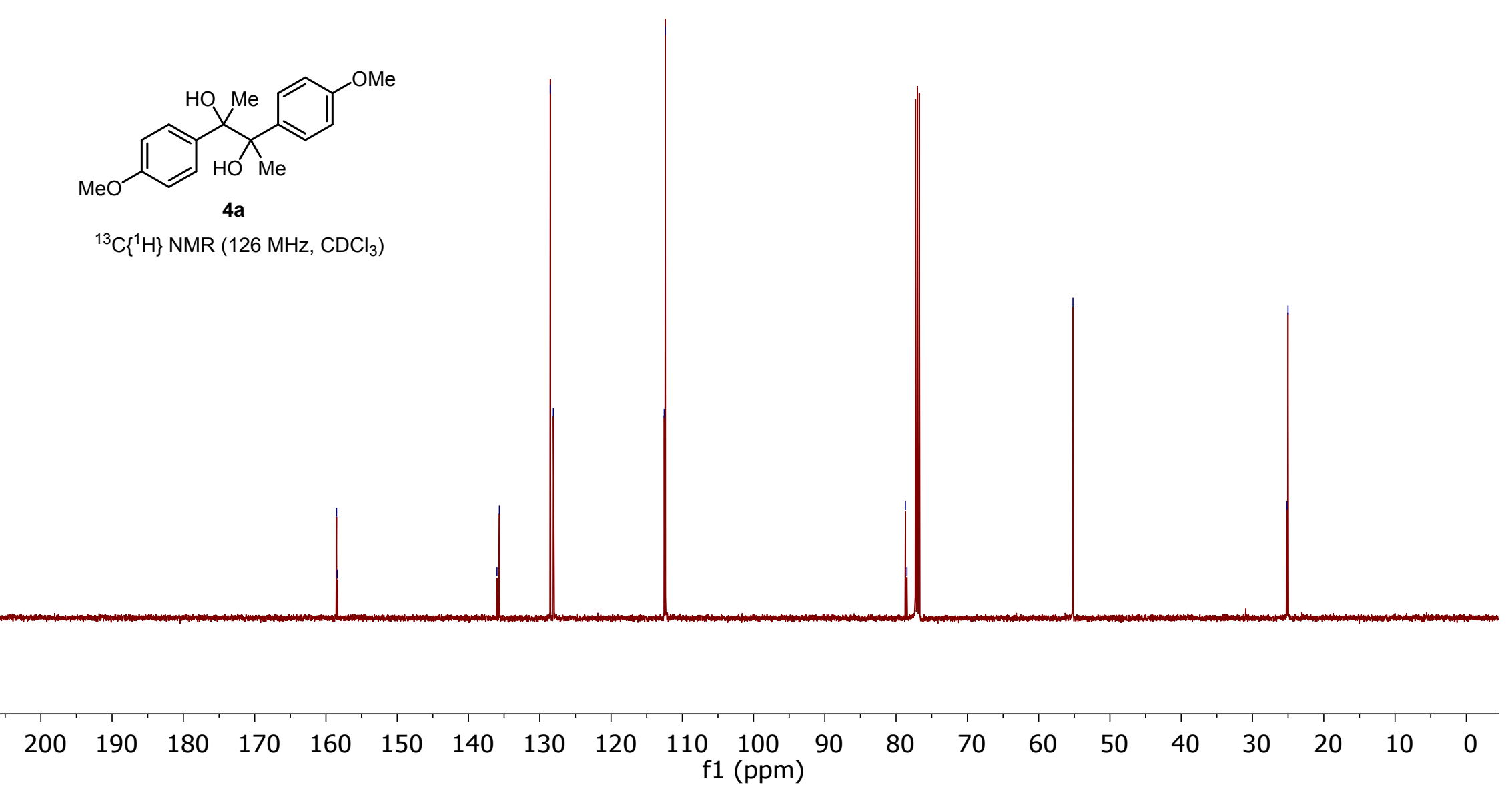


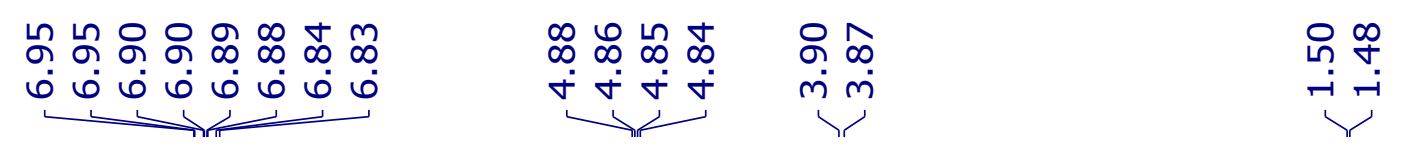

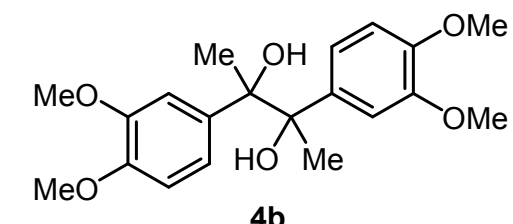

4b

${ }^{1} \mathrm{H}$ NMR (500 MHz, $\mathrm{CDCl}_{3}$ )

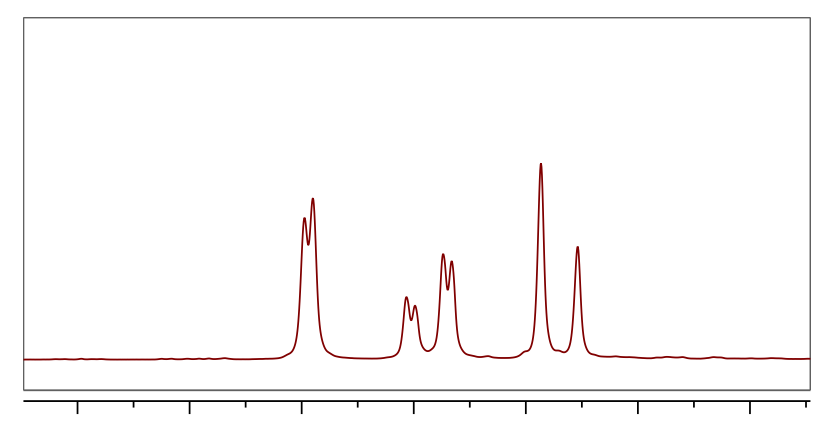

$\begin{array}{lllllll}7.05 & 7.00 & 6.95 & 6.90 & 6.85 & 6.80 & 6.75\end{array}$ f1 (ppm)
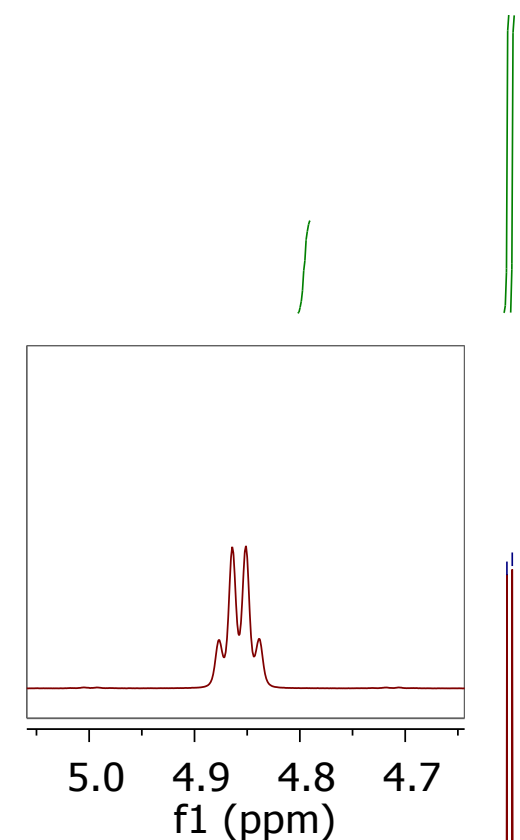

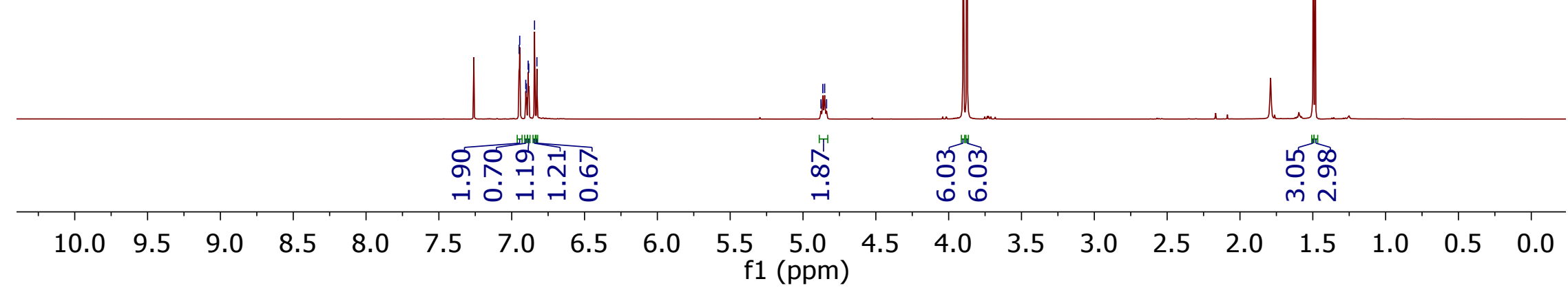




\begin{tabular}{|c|c|c|c|}
\hline 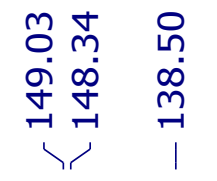 & 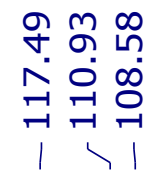 & $\begin{array}{l}\stackrel{n}{2} \\
\stackrel{2}{i} \\
1\end{array}$ & 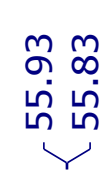 \\
\hline
\end{tabular}

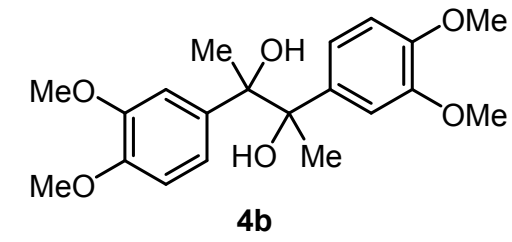

${ }^{13} \mathrm{C}\{\mathrm{H}\} \mathrm{NMR}\left(126 \mathrm{MHz}, \mathrm{CDCl}_{3}\right)$

$\begin{array}{lllllllllllllllllllllllll}200 & 190 & 180 & 170 & 160 & 150 & 140 & 130 & 120 & 110 & 100 & 90 & 80 & 70 & 60 & 50 & 40 & 30 & 20 & 10 & 0\end{array}$




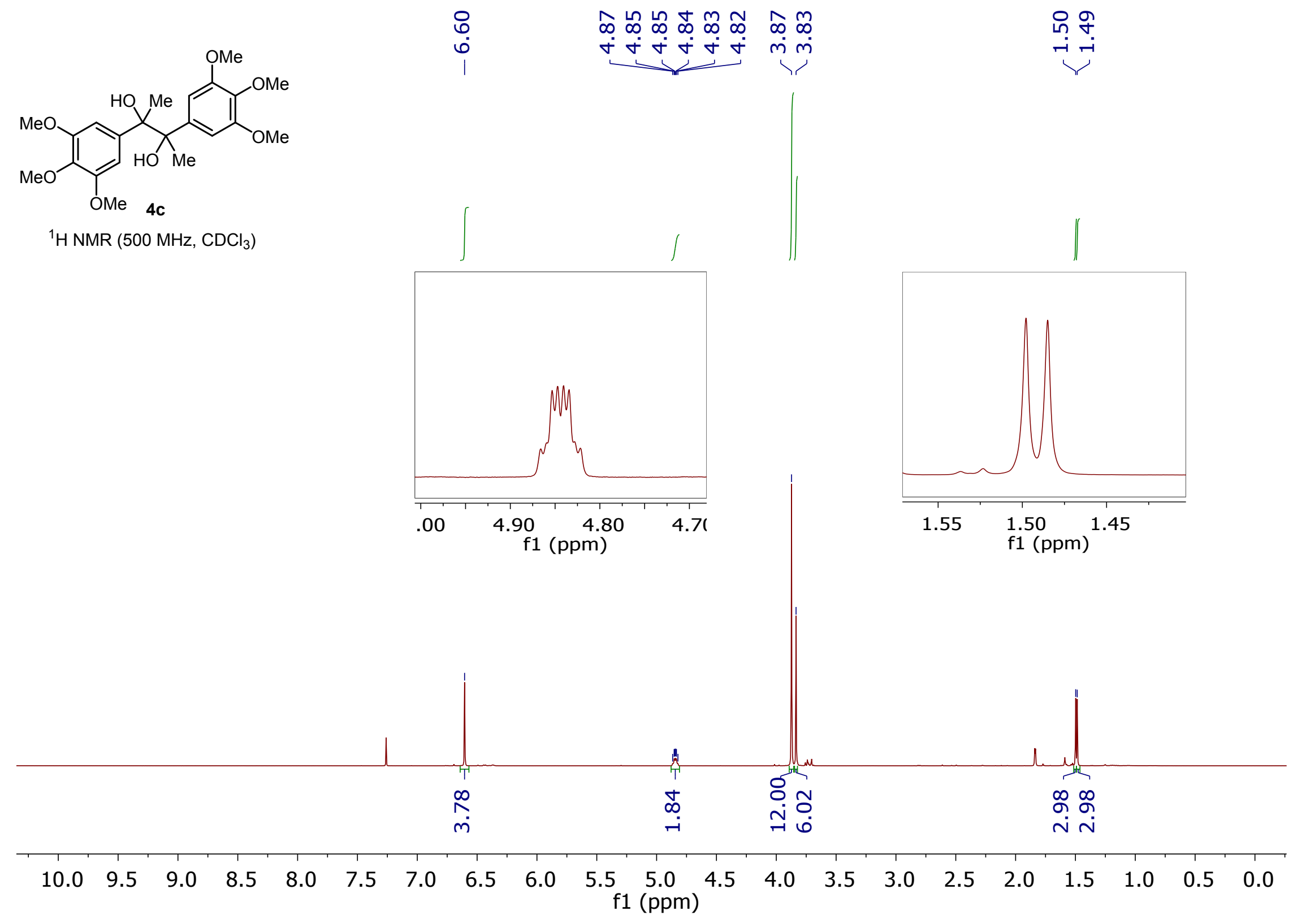




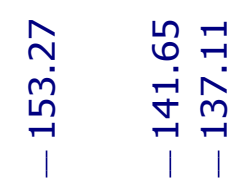

굴

ㅂ.

ำ

กี

กั

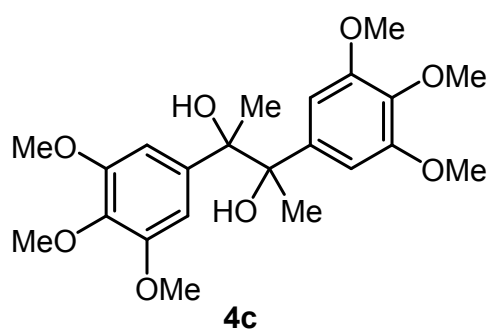

${ }^{13} \mathrm{C}\left\{{ }^{1} \mathrm{H}\right\} \mathrm{NMR}\left(126 \mathrm{MHz}, \mathrm{CDCl}_{3}\right)$

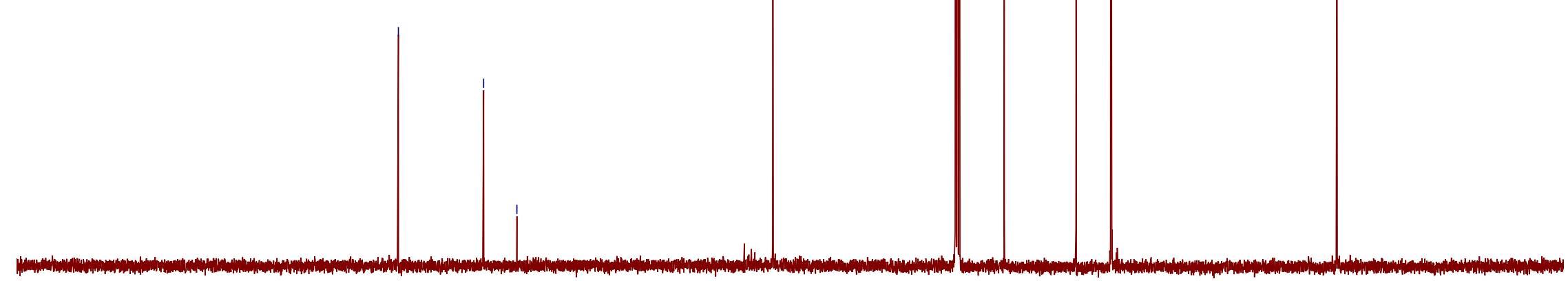

200

$190 \quad 180 \quad 170$

160

$150 \quad 140$

$130 \quad 120$ $\mathrm{f1}$ (ppm) 


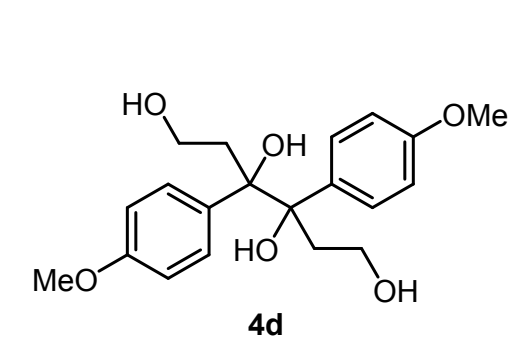

${ }^{1} \mathrm{H}$ NMR $\left(500 \mathrm{MHz}, \mathrm{MeCN}-\mathrm{d}_{3}\right)$
ڤ

$\wedge 6$
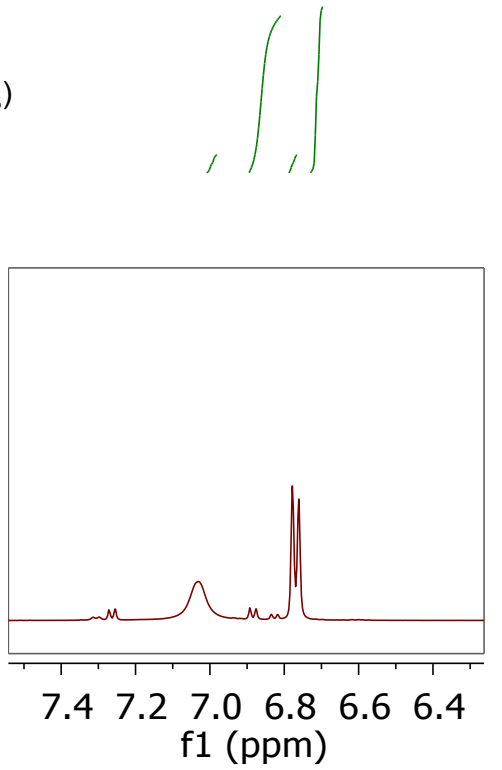

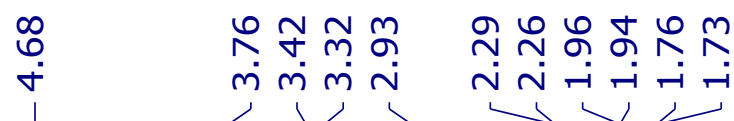

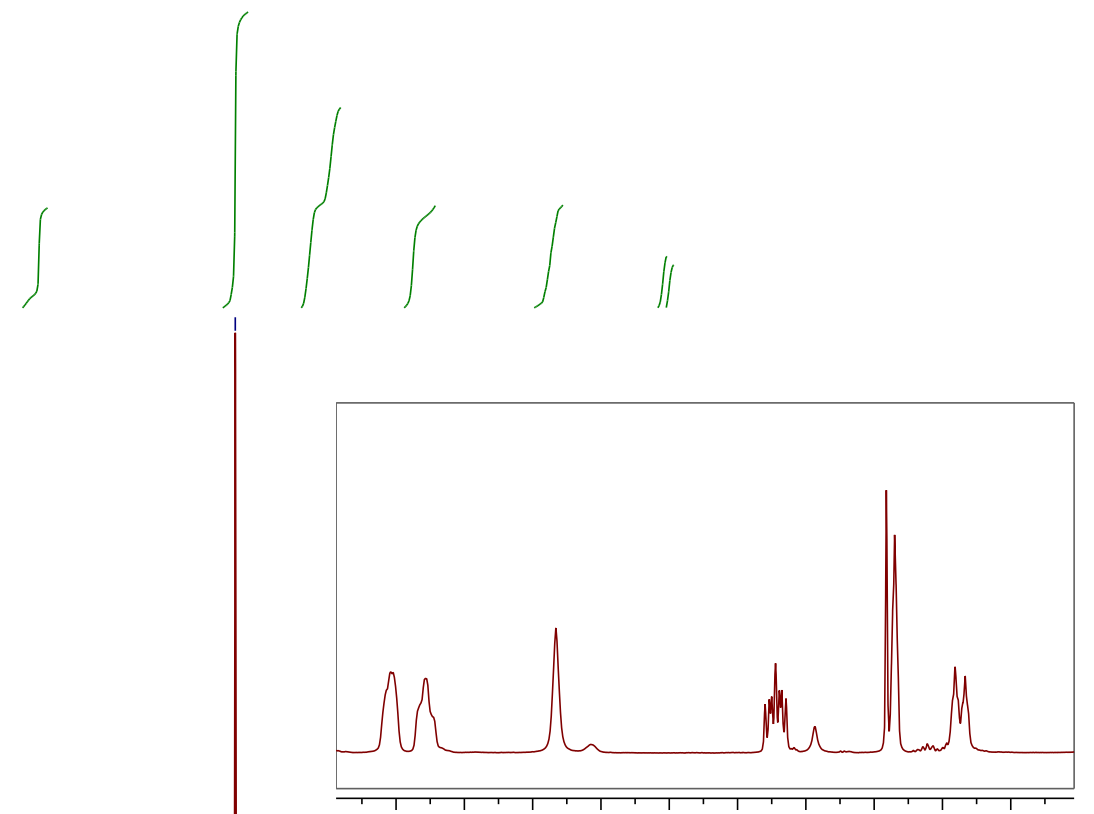

3.43 .23 .02 .82 .62 .42 .22 .01 .81 .6 f1 (ppm)

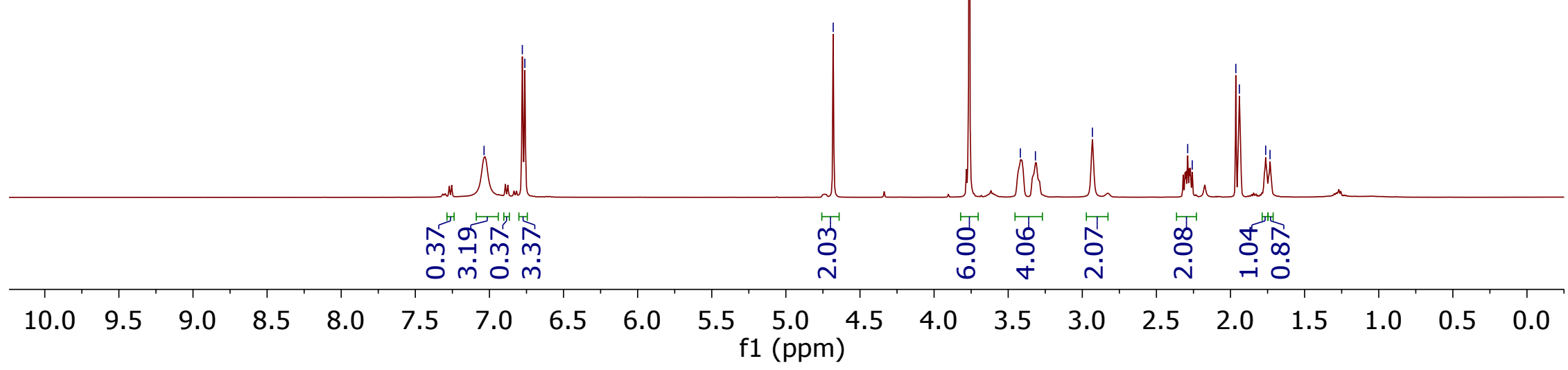



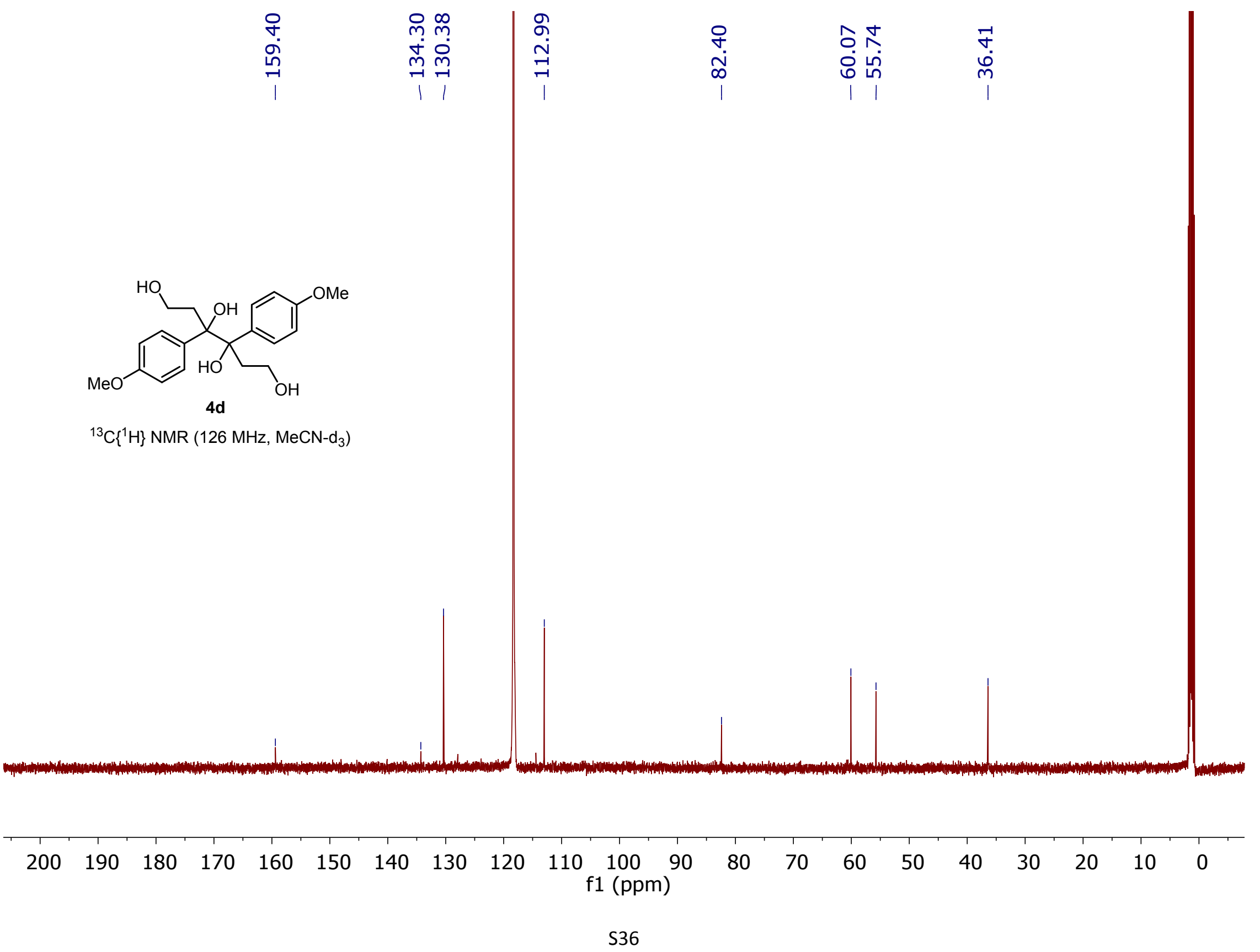


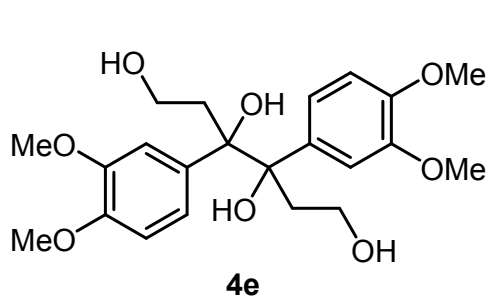

${ }^{1} \mathrm{H}$ NMR $\left(500 \mathrm{MHz}, \mathrm{CDCl}_{3}\right)$

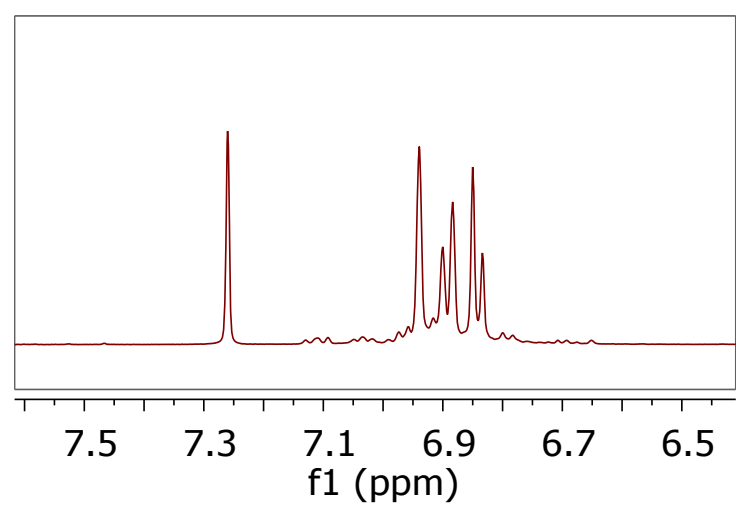

$\forall$ ○

6606

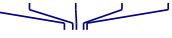

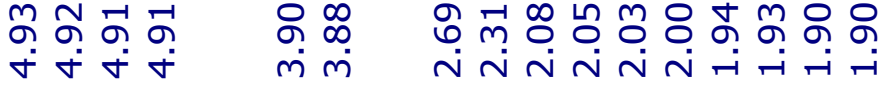

+
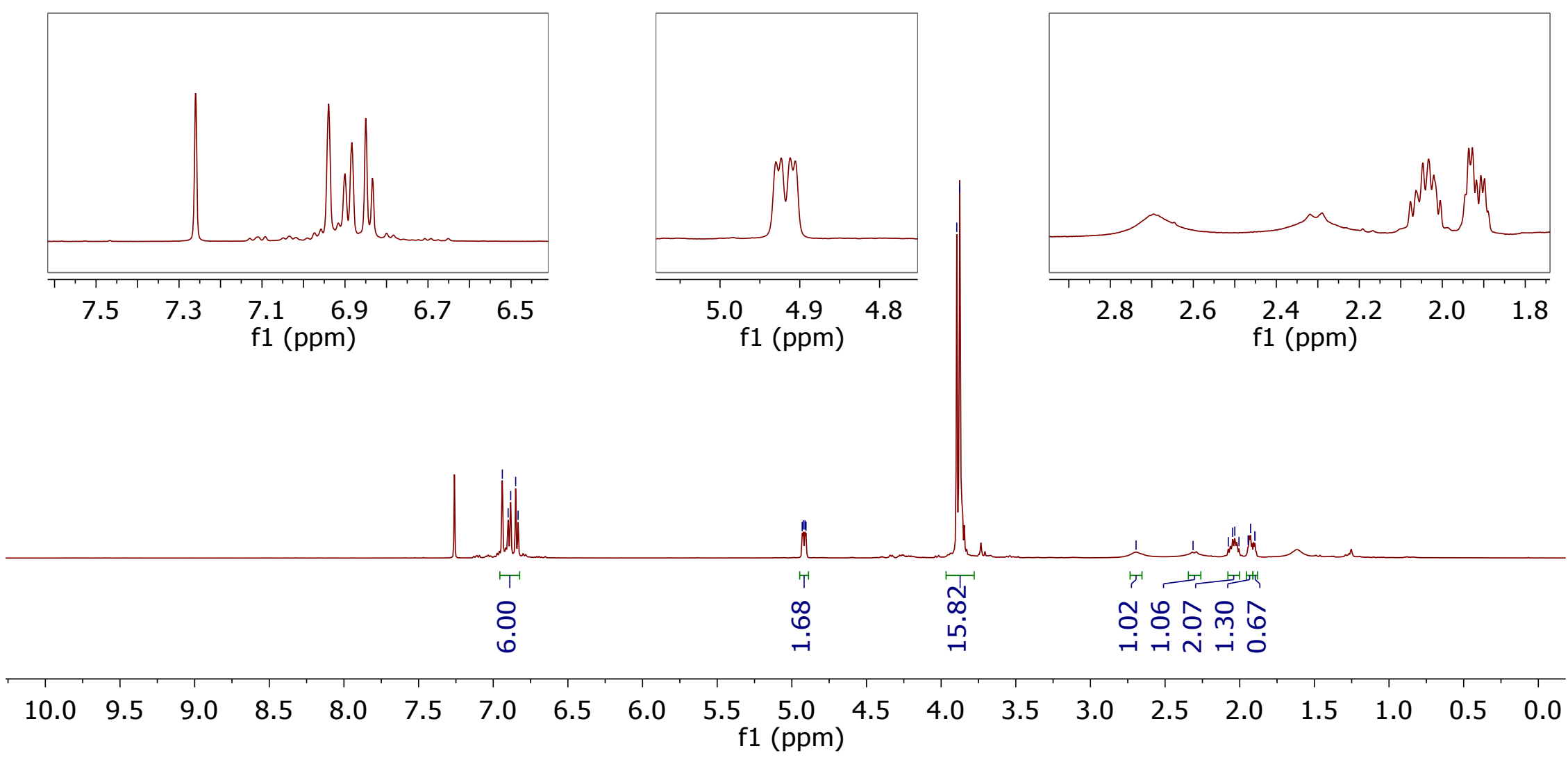


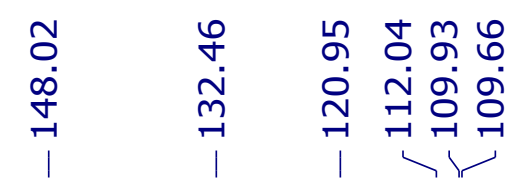

จำ

จั จิ นึ่ นึ่

$\checkmark$

ㄱㅇㅇ

ஸे ले

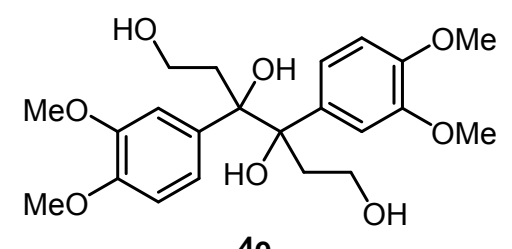

$4 e$

${ }^{13} \mathrm{C}\left\{{ }^{1} \mathrm{H}\right\} \mathrm{NMR}\left(126 \mathrm{MHz}, \mathrm{CDCl}_{3}\right)$ 


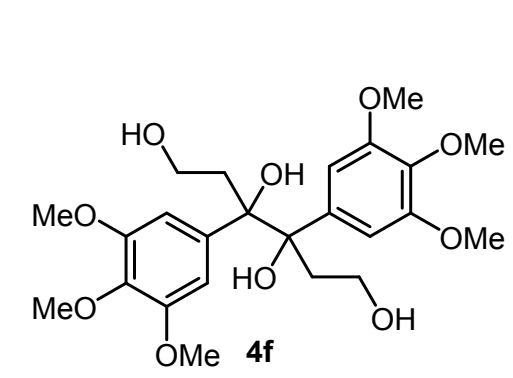

${ }^{1} \mathrm{H}$ NMR $\left(500 \mathrm{MHz}, \mathrm{CDCl}_{3}\right)$
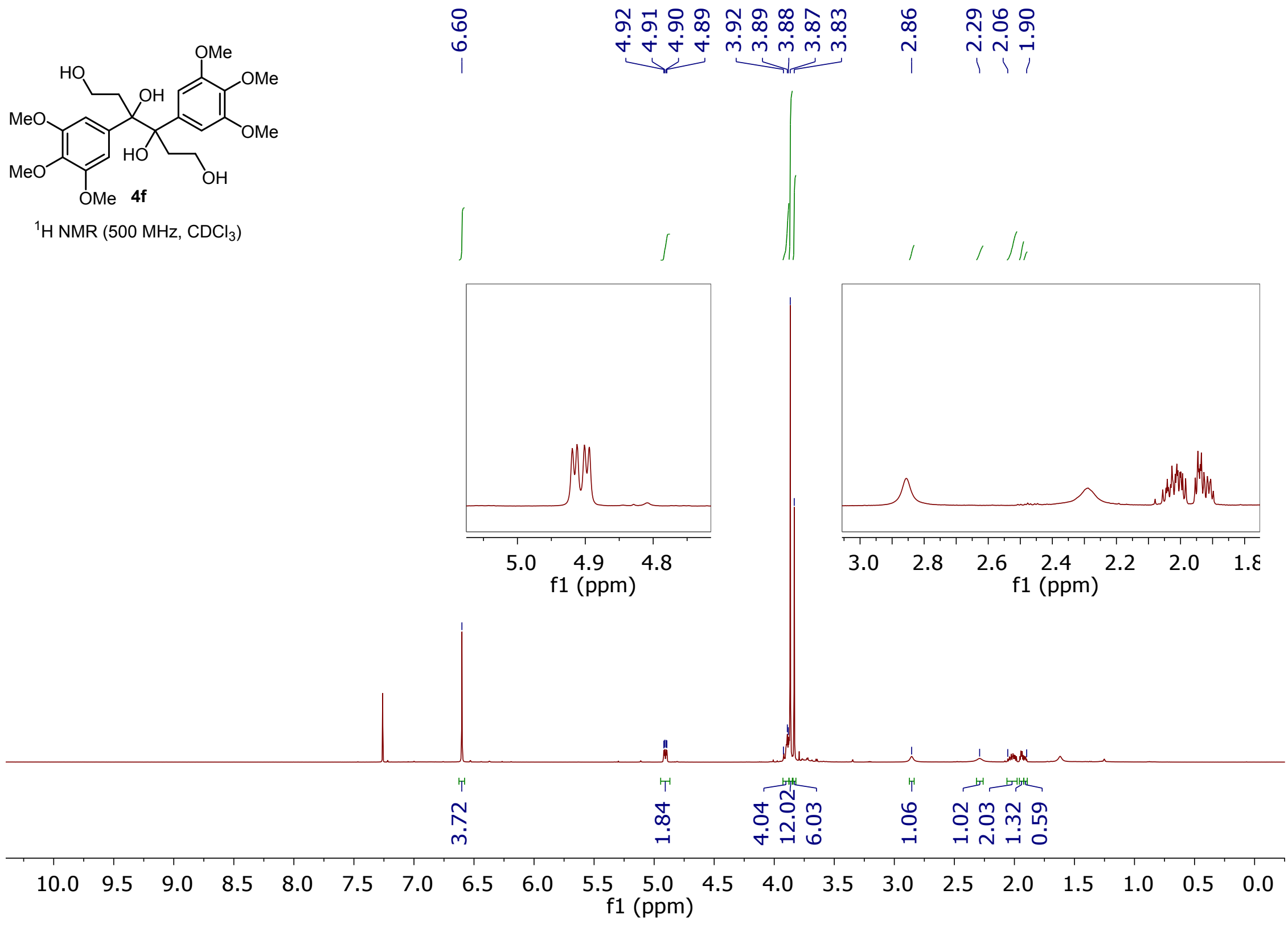


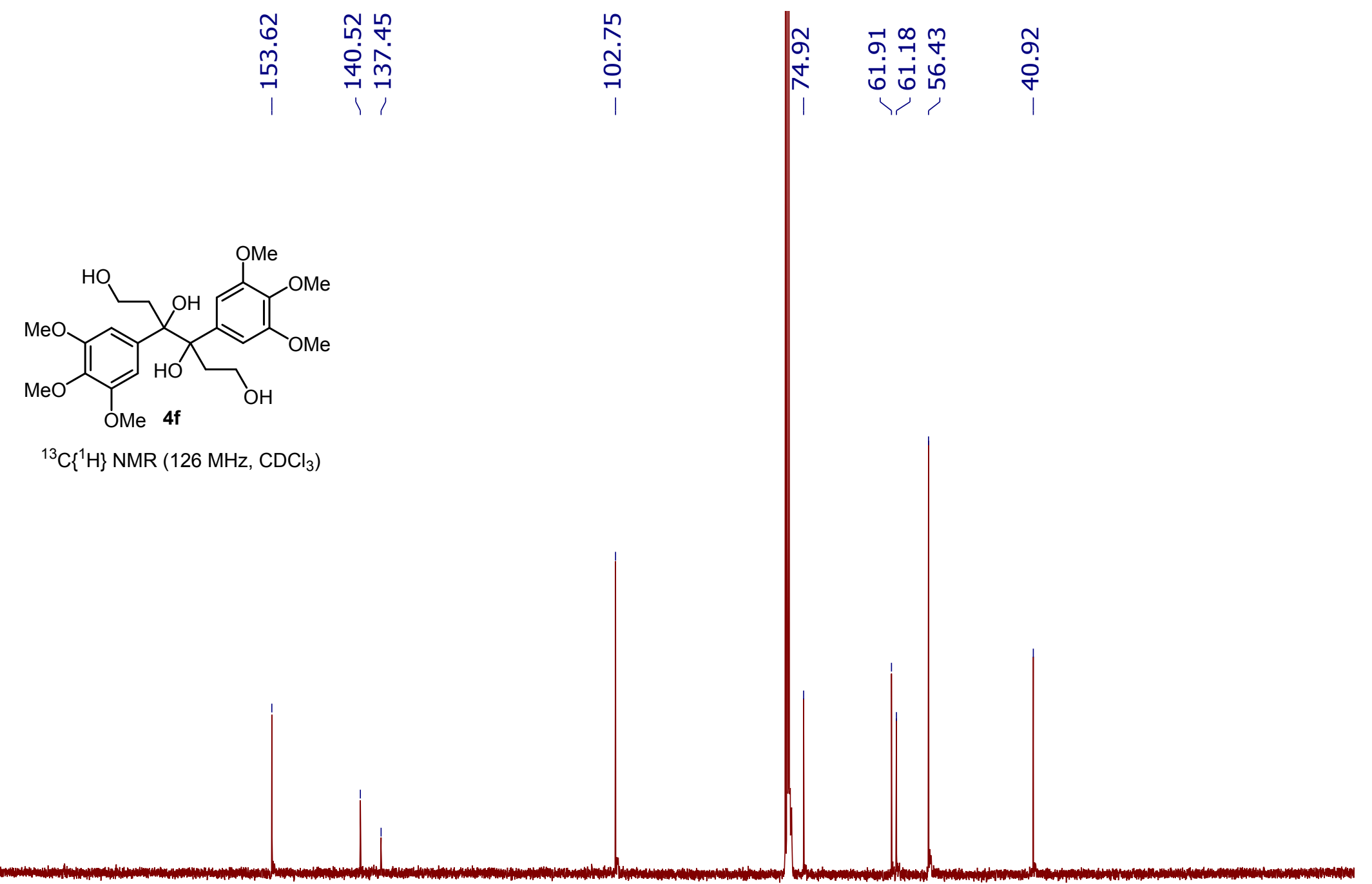

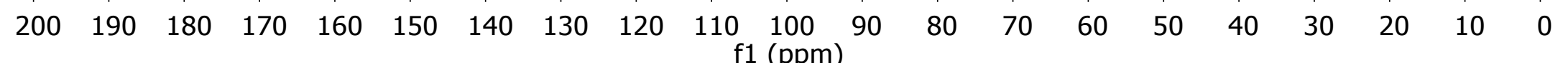




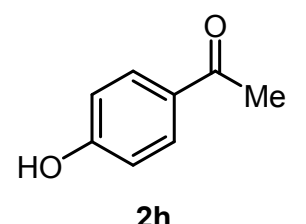

${ }^{1} \mathrm{H}$ NMR (500 MHz, $\mathrm{CDCl}_{3}$ )

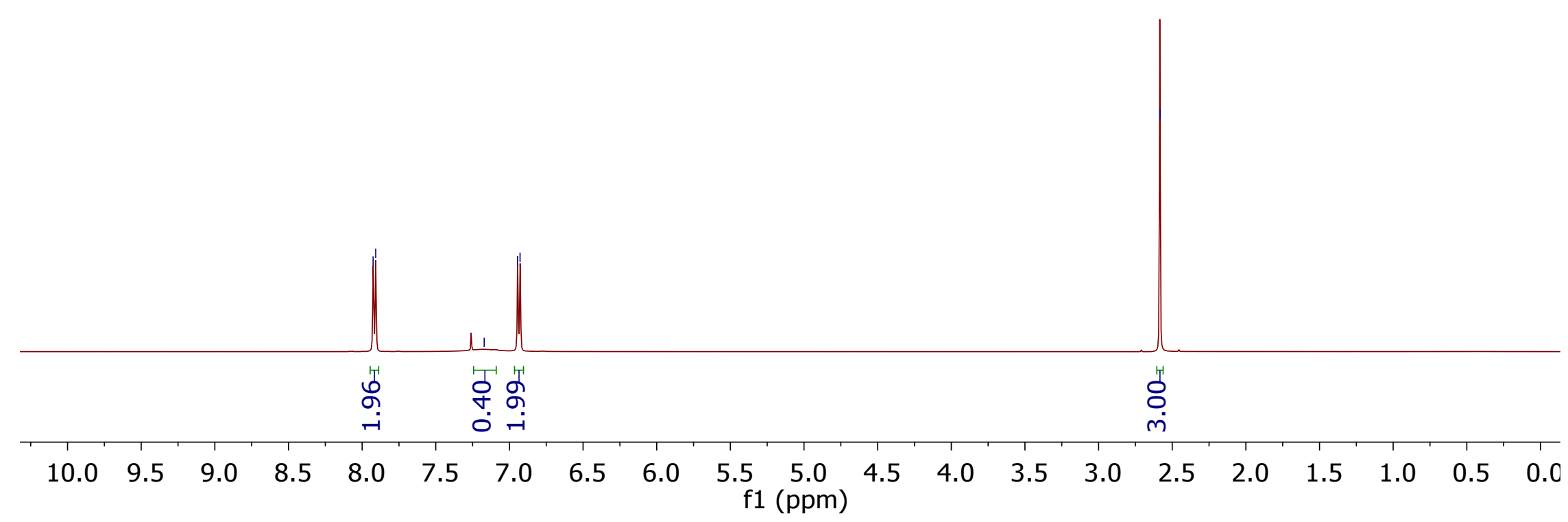




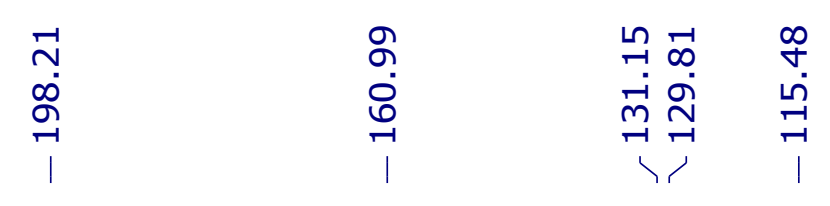

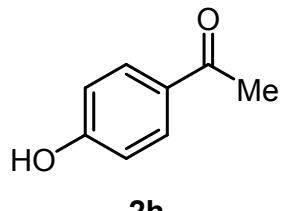

2h

${ }^{13} \mathrm{C}\left\{{ }^{1} \mathrm{H}\right\} \mathrm{NMR}\left(500 \mathrm{MHz}, \mathrm{CDCl}_{3}\right)$

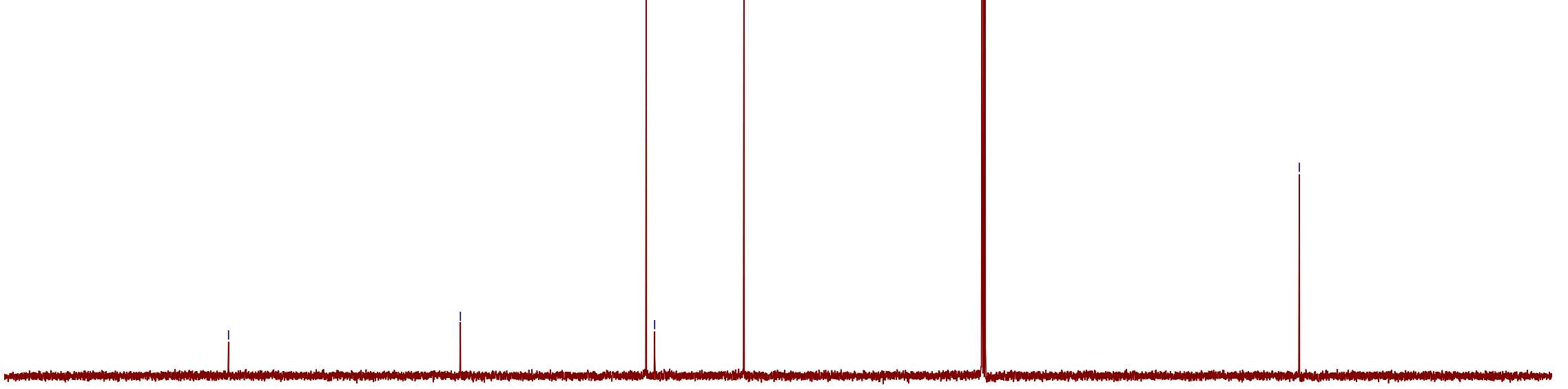

$\begin{array}{lllllllllllllllllllllllllllllllll}230 & 220 & 210 & 200 & 190 & 180 & 170 & 160 & 150 & 140 & 130 & 120 & 110 & 100 & 90 & 80 & 70 & 60 & 50 & 40 & 30 & 20 & 10 & 0 & -10\end{array}$ 